\title{
Firm Entry, Excess Capacity and Endogenous
}

\author{
Productivity
}

\author{
Anthony Savagar* Huw Dixon ${ }^{\dagger}$
}

October 2019

\begin{abstract}
We show that sluggish firm entry causes productivity to vary endogenously in response to technology shocks. The endogenous productivity effect is caused by incumbent firms utilizing excess capacity as entry adjusts. We develop a nonparametric model of endogenous sunk costs and monopolistic competition to show that imperfect competition and dynamic entry are necessary and jointly sufficient conditions for endogenous productivity fluctuations. Quantitatively we show the endogenous productivity effect is as large as that from a traditional 'capital utilization' effect.
\end{abstract}

*Corresponding author a.savagar@kent.ac.uk, University of Kent. Thanks to Leo Kaas, Frédéric Dufourt, Akos Valentinyi, David Baqaee, Swati Dhingra, Mathan Satchi, Ben Heijdra, Vivien Lewis, Jo Van Biesebroeck, Ricardo Reis and conference participants at SED Edinburgh 2017.

${ }^{\dagger}$ Cardiff University 
Recent empirical evidence and theoretical work in macroeconomics stresses the importance of non-instantaneous adjustment of firms over the business cycle. ${ }^{1}$ One important implication of this insight is that when shocks hit the economy they are initially borne by incumbent firms. Therefore the intertemporal behaviour of incumbents, between shock hitting and new firms entering, is important to understand business cycle fluctuations. In this paper we show that if incumbents utilize excess capacity over this short-run period, it can create sizeable endogenous productivity effects.

The paper makes two contributions: first, it describes an analytically tractable, continuous time model of firm entry and imperfect competition over the business cycle that is able to replicate the main firm-dynamics, business-cycle facts; second, it shows that measured TFP is endogenously procylical following technology shocks in models that exhibit two features: dynamic entry and imperfect competition. The main result, Theorem 1, states these as necessary and jointly sufficient conditions. Imperfect competition is necessary because it creates increasing returns to scale as firms underutilize their overhead costs. Dynamic firm entry is necessary because it creates a short-run period for incumbents to exploit these increasing returns, free from business stealing. Quantitatively we show that the size of our endogenous productivity effect is similar to the well-known endogenous productivity effect from a traditional 'capital utilization' (endogenous depreciation) effect a la Greenwood, Hercowitz, and Huffman 1988. Our model is parsimonious, so the theorem applies to a burgeoning line of research that incorporates dynamic firm entry and imperfect competition over the business cycle (following Bilbiie, Ghironi, and Melitz 2012).

To understand the mechanism generating endogenously procyclical measured TFP, consider a positive technology shock. With dynamic firm entry and standard capital accumulation, both capital and number of firms are fixed stocks in the short run (quasifixed). ${ }^{2}$ Therefore the technology improvement is initially borne by incumbents with

\footnotetext{
${ }^{1}$ Bilbiie, Ghironi, and Melitz 2012 provide the seminal work on dynamic firm entry in macroeconomics. Tian 2018 provides an empirical survey of the procylical and dynamic nature of firm adjustment.

2 This is the Marshallian definition of the short-run: at least one factor of production is fixed, and firm entry is yet to adjust. Often it is not present in macroeconomic models as firms are fixed or instantaneously adjust, despite capital usually being a quasi-fixed input.
} 
quasi-fixed capital. In order to maximize profits, these incumbents instantaneously increase their output (intensive margin), and in turn productivity increases through returns to scale that arise under monopolistic competition with overhead costs. However, after the short-run period, firms begin to enter to arbitrage incumbents' profits. The entrants steal business, which reverses the incumbents' increases in intensive margin and corresponding profits until scale returns to its initial level and profits are zero in the long run. Thus entry reverses the short-run productivity fluctuation, and if entry is faster, productivity reversion is faster. ${ }^{3}$

In the literature on microproduction theory and efficiency analysis, capacity utilization is the ratio of actual output to some measure of potential output (full capacity) given a firm's short-run stock of capital and other quasi-fixed factors of production (Nelson 1989). ${ }^{4}$ In our work the potential output benchmark will be the firm's 'minimum efficient scale' which minimizes long-run average cost (and arises under perfect competition). Introductory treatments of monopolistic competition refer to this as capacity output, and excess capacity is underproduction relative to this level (Hall and Lieberman 2009, Ch. 11). Importantly it is distinct from the same term often used in RBC research to mean the more specific concept of capital utilization and endogenous depreciation, which also creates endogenous productivity fluctuations (King and Rebelo 1999). ${ }^{5}$

Our model matches a number of business-cycle, firm-dynamics facts that have come under recent attention. It implies that 'less competitive' (higher markup) economies have greater excess capacity, greater returns to scale and greater productivity fluctuations. Under perfect competition these fluctuations do not arise. Therefore imperfect competition (markups) and measured TFP volatility are positively related. Our model

\footnotetext{
${ }^{3}$ The mechanism is similar to that which generates endogenous, procylical productivity movements to non-technology shocks when firms are fixed (Hornstein 1993, Basu and Fernald 2001). A favorable permanent, one-time shock to marginal costs causes incumbent firms to expand output (intensive margin increase), and with increasing returns productivity increases. However, with no role for entry, this implies a permanent increase in firm scale and productivity, not an overshooting-as excess capacity is utilizedthen reversion as firms enter, undo the intensive margin excess capacity effect, and expand the extensive margin.

${ }^{4}$ Morrison 2012 and Nadiri and Prucha 2001 give overviews, also see footnote 10.

${ }^{5}$ To be clear, we refer to our mechanism as 'excess capacity utilization' or 'capacity utilization', whereas the Greenwood, Hercowitz, and Huffman 1988 mechanism is always 'capital utilization'. Fagnart, Licandro, and Portier 1999 note our distinction.
} 
generates pro-cyclical firm scale and profits. Recovery speeds are positively related to net entry rates, and firm adjustment is slower than capital adjustment. In figure 1 we show the procylical relationship between output, excess capacity utilization and net entry for quarterly US data which our model is able to replicate. ${ }^{6}$ The correlation between GDP and net entry is 0.64 and between GDP and capacity utilization is 0.84 . Procylical net entry is robustly documented by Bergin and Corsetti 2008; Tian 2018.

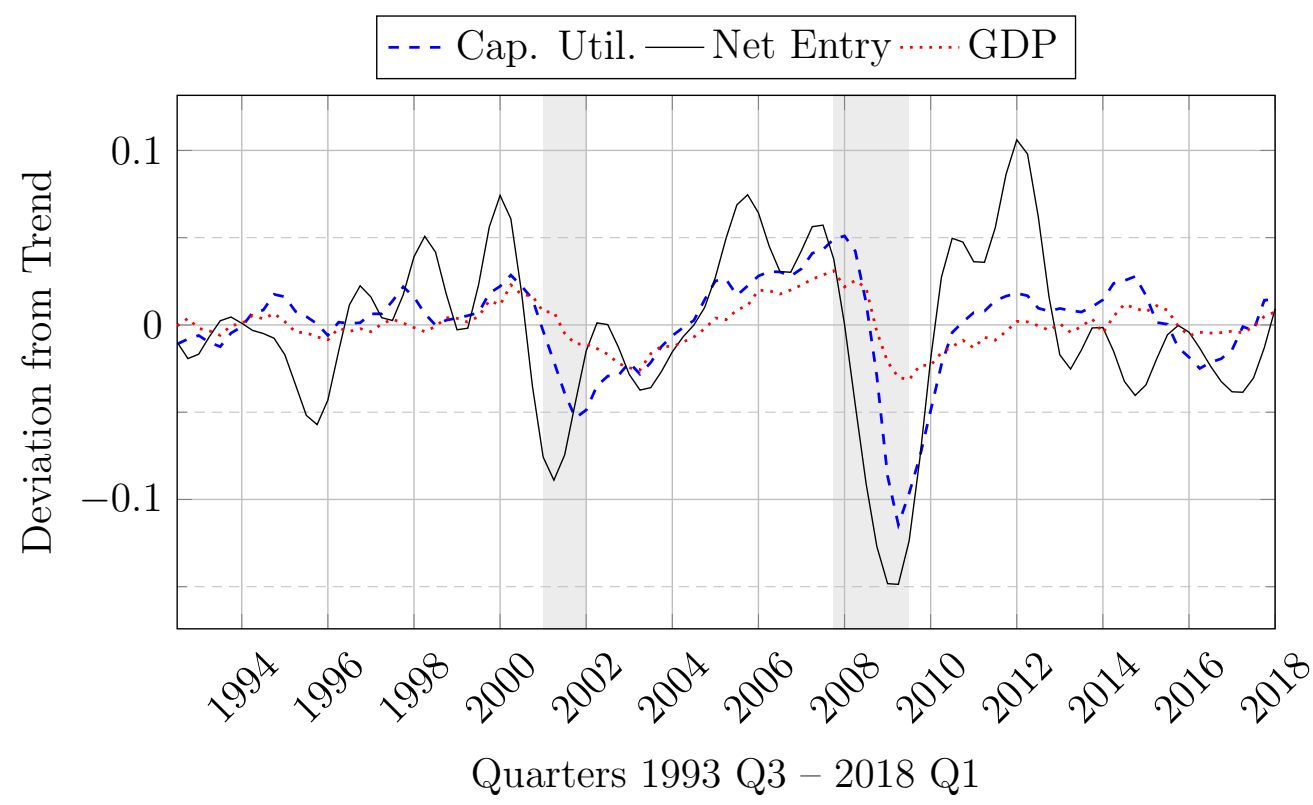

Figure 1: US Procylical Capacity Utilization and Net Entry

Morrison 1992; Berndt and Morrison 1981 and Berndt and Fuss 1986 emphasize the positive relationship between productivity and capacity utilization in our context. Additionally in our model net entry lags output growth as documented by Campbell 1998 and in emerging evidence by Rossi and Chini 2016 (US data 1977-2013). Figure 2 presents $\operatorname{VAR}(2)$ orthogonalized impulse responses to a technology shock. The results verify the mechanisms in our theory are consistent with quarterly US data 1992-2017. ${ }^{7}$ Following an exogenous technology shock, output and capacity utilization (CU) expand. Simultaneously there is an increase in profits which corresponds to a rise in net entry (NE) that

\footnotetext{
${ }^{6}$ See Appendix $\mathrm{H}$ for data description.

${ }^{7}$ Appendix F derives the model consistent technology series. Technology shocks are identified through a Cholesky decomposition where the ordering of variables is consistent with economic theory: technology initially affects capacity utilization, which expands profits and output, then subsequently firm entry responds. These dynamics are robust to alternative specifications. The initial shock is a 1 s.d. (0.0043) shock to technology. Appendix $\mathrm{H}$ discusses the data.
} 
stays positive until profits have dissipated.

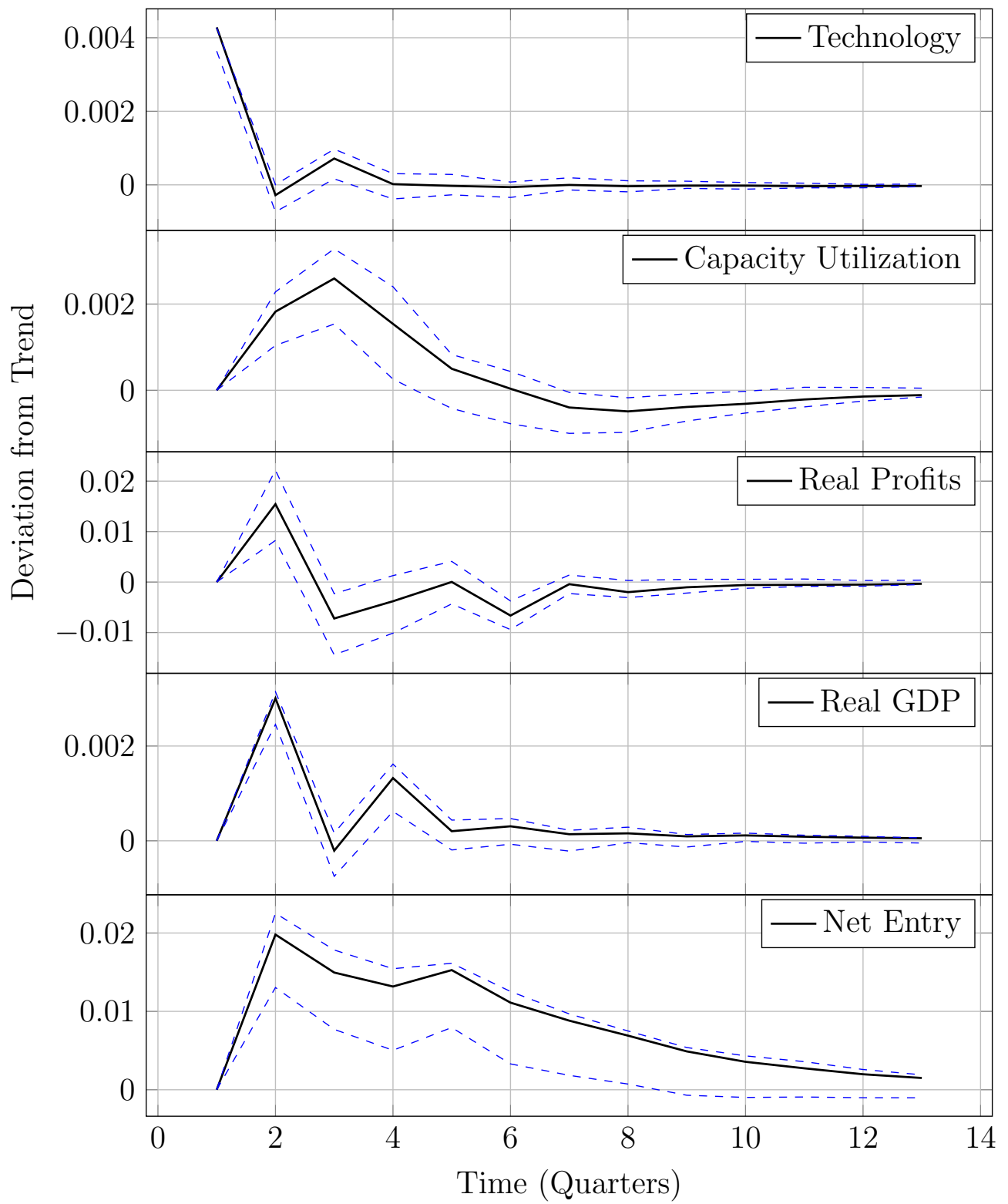

Figure 2: VAR(2) Orthogonal Impulse Response (1 s.d. confidence intervals)

We develop a Ramsey-Cass-Koopmans model with endogenous labour, capital accumulation, monopolistic competition and dynamic entry. Dynamic entry occurs through an endogenous sunk cost that depends on entry congestion. Since the sunk cost is increasing in entry, a prospective entrant has an incentive to delay entry if the net present value of incumbency is less than the sunk cost, and in turn the sunk cost will diminish in the future if less entry takes place today. In long-run steady state there is no role for firm dynamics. Entry is zero, profits are zero and the sunk cost is zero so the static out- 
comes are the same as a model without entry or sunk costs. Our interest is the short-run transition to this zero-profit, zero-entry steady state. Our model is deterministic and in continuous time and we study transition under an unexpected once-and-for-all technology shock.

The model has two state variables: capital and number of firms. Consequently capital per firm is quasi-fixed because state (predetermined) variables cannot adjust instantaneously. Whereas, labour (through consumption) and entry can jump on impact to put the economy on its stable manifold which is defined by capital and number of firms. Subsequently the economy evolves along this stable manifold as capital per firm adjusts. Our theoretical contribution is to show that our model which is defined by four endogenous variables (consumption, entry, capital, number of firms) always has two positive and two negative eigenvalues. This implies that it is always determinate, and has a two dimensional stable manifold (a saddle path exists), which formalizes the Marshallian definition of the short run in a macro DGE context. ${ }^{8}$

Related Literature The most relevant papers for this research are Datta and Dixon 2002; Jaimovich and Floetotto 2008 and Bilbiie, Ghironi, and Melitz 2012 (BGM). Datta and Dixon 2002 provide a continuous time dynamic entry model in a partial equilibrium IO environment that we adapt to a macroeconomic general equilibrium environment, as in Brito and Dixon 2013 under perfect competition. Jaimovich and Floetotto 2008 investigate endogenous productivity with firm entry through the channel of endogenous markups, but entry is static (instantaneous), so profits are always zero. ${ }^{9}$ BGM has popularized dynamic entry in business cycle modeling by providing a quantitative model that improves moment matching. This framework has been successfully adopted to show the importance of dynamic entry in several studies (Etro and Colciago 2010; Lewis and Poilly 2012; Lewis and Stevens 2015; Lewis and Winkler 2017). Early versions of this work (Bilbiie, Ghironi, and Melitz 2007) alluded to the distorting effects of entry and variety on productivity measurement. We develop this insight into a tractable setting

\footnotetext{
${ }^{8}$ See footnote 2.

${ }^{9}$ Jaimovich and Floetotto 2008 provide an appendix with the dynamic extension to their model. It is a quantitative exercise focused on the endogenous markups channel.
} 
with a focus on overhead costs rather than variety effects. We use a related dynamic entry setup, based on endogenous sunk costs, that offers tractability. It is conceptually and mathematically similar to BGM in the sense that there are two state variables in capital and number of firms, but the sunk cost endogenously varies with the flow of entrants, which has been shown to be important in macroeconomics by Lewis 2009; Poutineau and Vermandel 2015; Bergin, Feng, and Lin 2016. We exclude endogenous markups, instead using a monopolistic competition setup with fixed markups and firms with Ushaped average cost curves. The production function is nonparametric as in Rotemberg and Woodford 1999, and in parametric form is similar to a number of papers that also explore the business cycle propagation effects of firm entry Devereux, Head, and Lapham 1996; Ambler and Cardia 1998; Cook 2001; Kim 2004. Our paper extends this line of research with the recent dynamic entry literature discussed above, emphasizing that it is crucial to take into account the short-run period in which incumbents bear shocks, and adjust their intensive margin, if we are to fully understand productivity movements.

Hall 1986 emphasizes that measured TFP has important endogenous components. Hall 1987 explains productivity procylicality arises from variations in output per firm that lead to movements down the average cost curve. Our contribution is to microfound sluggish entry as an explanation for why this movement down the average cost curve happens temporarily, and link it to microproduction theory on excess capacity utilization and quasi-fixity. ${ }^{10}$ We focus on the delay in the demand curve shifting, as firms are quasifixed, which causes short-run monopolistic profits and endogenous productivity as excess capacity varies intertemporally. Whereas the papers by Devereux, Head, and Lapham 1996; Chatterjee and Cooper 2014 and Jaimovich and Floetotto 2008 explain how entry causes endogenous productivity movements by changing the slope of demand curves in the long run (which is equivalent to the short run since they have instantaneous firm entry i.e. instantaneous zero profits). In these papers the slope of the demand curve changes either through endogenous markups or increasing returns aggregation. Our work generalizes these papers that have instantaneous entry with papers that have a fixed

\footnotetext{
10 Morrison 2012; Nadiri and Prucha 2001; Berndt and Morrison 1981; Hulten 1986.
} 
number of firms (Blanchard and Kiyotaki 1987; Hall 1990; Rotemberg and Woodford 1992; Hornstein 1993), so that rather than an immediate extensive margin adjustment, or a permanent intensive margin adjustment, in the short-run the intensive margin adjusts, but is unchanged in the long-run as the extensive margin compensates. ${ }^{11}$ The business stealing effect of entry decreasing incumbents' output (intensive margin) and profits was analyzed by Mankiw and Whinston 1986 in industrial organization literature with integer firms, and international trade literature has used it to explain falling measured TFP of domestic producers following foreign entry (Harrison and Aitken 1999).

\section{Model}

\subsection{Household}

The economy consists of a continuum of infinitely-lived identical households who maximize utility subject to a resource constraint.

$$
\begin{aligned}
\max \mathrm{U}: & =\int_{0}^{\infty} u(C(t), 1-L(t)) e^{-\rho t} d t \\
\text { s.t. } \quad \dot{K}(t) & =r K(t)+w L(t)+D(t)-C(t)
\end{aligned}
$$

Individual utility $u: \mathbb{R}_{+} \times[0,1] \rightarrow \mathbb{R}_{+}$is strictly increasing in consumption $u_{C}>0$ and strictly decreasing in labour $u_{L}<0$. Both goods are normal $u_{C C}, u_{L L}<0$, so marginal utility of consumption and disutility of labour are diminishing, and utility is additively separable $u_{C L}=0 . \rho \in(0,1)$ is the discount factor over time $t \in \mathbb{R}_{+} \cdot{ }^{12}$ The household owns capital $K \in \mathbb{R}_{+}$, which does not depreciate, and it takes equilibrium rental rate $r$ and wage rate $w$ as given by the market rate (determined in section (1.2)). ${ }^{13}$ Households own firms and receive firm profits $D \in \mathbb{R}$. Solving the optimization problem simplifies to three conditions for optimal consumption and labour. ${ }^{14}$ They are the intertemporal

\footnotetext{
${ }^{11}$ These two cases arise in our model as limiting cases of the endogenous sunk cost.

${ }^{12}$ For clarity we follow the continuous time literature by suppressing time dependence $X(t)$ to $X$ after initial introduction.

${ }^{13}$ Section 5.3 introduces depreciation.

${ }^{14}$ Supplementary appendix solves the Hamiltonian problem.
} 
consumption Euler equation (3), intratemporal labour-consumption trade-off (4) and the resource constraint (2).

$$
\begin{aligned}
\dot{C} & =\frac{C}{\sigma(C)}(r-\rho), \quad \text { where } \sigma(C)=-C \frac{u_{C C}(C)}{u_{C}(C)} \\
w & =-\frac{u_{L}(L)}{u_{C}(C)}
\end{aligned}
$$

The two boundary conditions for a unique solution are

$$
\begin{aligned}
K_{0} & =K(0) \\
\lim _{t \rightarrow \infty} K(t) u_{C}(t) e^{-\rho t} & =0
\end{aligned}
$$

\subsection{Firm Production and Strategic Interactions}

There is monopolistic competition in the product market and perfect competition in the factor market, so firms are price setters for their output, and price takers for their inputs. Since each firm faces the same factor prices resources are divided equally among firms in symmetric equilibrium. Per firm variables are in lower case where $N \in \mathbb{R}_{+}$is the measure of firms, and we suppress time dependence notation for clarity.

$$
\begin{aligned}
k & \equiv \frac{K}{N}, \\
l & \equiv \frac{L}{N}
\end{aligned}
$$

$Y: \mathbb{R}_{+}^{2} \supseteq(N, y) \rightarrow \mathbb{R}_{+}$is the final good and is a constant-returns CES aggregate of each $i \in N$ firms' output.

$$
Y=N^{1-\frac{\theta}{\theta-1}}\left[\int_{0}^{N} y(i)^{\frac{\theta-1}{\theta}} d i\right]^{\frac{\theta}{\theta-1}}
$$

A firm is a 1-firm industry, so $\theta \in(1, \infty)$ is intersector substitutability. ${ }^{15}$ The $N^{1-\frac{\theta}{\theta-1}}$ component removes love-of-variety. With the unit price of the aggregate good as the numeraire the sectoral demand $y(i)$ directed at each 1-firm industry takes constant elasticity

\footnotetext{
${ }^{15}$ Sector, firm, industry and product are synonyms in this model.
} 
form

$$
y(i)=p(i)^{-\theta} \frac{Y}{N}, \quad \forall i \in(0, N)
$$

with inverse demand for industry $i$ given by $p(i)$. Firms have the same production technology

$$
y=\max \{A F(k, l)-\phi, 0\}
$$

where $F: \mathbb{R}_{+}^{2} \supseteq(k, l) \rightarrow \mathbb{R}_{+}$is a firm production function with continuous partial derivatives which is homogenous of degree $\nu \in(0,1)$ (hod- $\nu$ ) on the open cone $\mathbb{R}_{+}^{2}$, and $\phi \in \mathbb{R}_{++}$is an overhead cost denominated in output. $F$ has concavity properties $F_{k}, F_{l}, F_{k l}=F_{l k}>0, F_{k k}, F_{l l}<0, F_{k k} F_{l l}-F_{k l}^{2}>0$, and $A \in \mathbb{R}_{++}$is a technology parameter. This production function gives a U-shaped average cost curve because there are initially increasing returns from the overhead, but these diminish due to increasing marginal costs in the production function. The increasing marginal costs assumption $v \in(0,1)$ is necessary for existence of a perfectly competitive equilibrium when there are positive overhead costs. If we study constant returns $\nu=1$, results only exist under imperfect competition. This precludes the perfect competition benchmark we use to study capacity utilization ${ }^{16}$ The overhead cost is the nonconvexity which prevents some firms producing, and it occurs each period, which distinguishes it from the entry cost that is paid once to enter (see section 1.3). The increasing returns that $\phi$ causes is a common outcome in the firm entry in macroeconomics literature (e.g. Jaimovich and Floetotto 2008; Devereux, Head, and Lapham 1996). ${ }^{17}$ Under symmetry aggregate output is

$$
Y=N y
$$

From (11), firm production is homogeneous of degree 0 (hod-0) in aggregate inputs $(K, L, N)$, whereas the aggregate production function (12) is hod-1 in $(K, L, N)$. For example, double all inputs (capital, labour and number of firms): firm output is unaf-

\footnotetext{
${ }^{16}$ On some occasions we shall remark on the constant returns case, but assume $\nu \in(0,1)$ unless otherwise stated.

${ }^{17}$ As in Jaimovich 2007; Rotemberg and Woodford 1992; Devereux, Head, and Lapham 1996; Chatterjee and Cooper 1993 the role of overhead costs is to reproduce zero profits despite market power.
} 
fected, but aggregate output doubles since there are twice as many firms all producing the same output. Therefore the intensive margin $y$ is unchanged, but the extensive margin $Y$ doubles.

Under monopolistic competition a firm maximises profits subject to sectoral demand (10) and its production function (11), taking real wage $w$, interest rates $r$ and aggregate output $Y$ as given. The result is the following factor market equilibrium, where the Lerner Index is the inverse of intersector substitutability $\zeta=\frac{1}{\theta} \in[0,1)$.

$$
\begin{aligned}
& A F_{k}(k, l)(1-\zeta)=r \\
& A F_{l}(k, l)(1-\zeta)=w
\end{aligned}
$$

This shows that the marginal revenue product of capital equates to the cost of capital and the marginal revenue product of labour equates to the wage. The Lerner Index of market power is the difference between price and marginal cost as a proportion of price $\left(\frac{P-M C}{P}\right)$ i.e. the price-cost margin. The limits capture no market power $\zeta=0$ when goods are highly substitutable (perfectly elastic demand) and total market power $\zeta \rightarrow 1$ when goods are completely differentiated. ${ }^{18}$

\subsubsection{Costs, Operating Profit and TFP}

Under the equilibrium factor market outcomes (13)-(14), total variable costs are decreasing in imperfect competition $\zeta .{ }^{19}$

$$
w l+r k=(1-\zeta) \nu A F(k, l)
$$

Conversely operating profits $d=y-w l-r k$ are increasing in imperfect competition

$$
d=(1-(1-\zeta) \nu) A F(k, l)-\phi
$$

The extra profit $\zeta \nu A F(k, l)$ from imperfect competition relative to perfect competition causes a static inefficiency which can lead to excessive entry. There is a distortion between

\footnotetext{
${ }^{18}$ In terms of a 'price-over-marginal-cost' markup $\mu=\frac{1}{1-\zeta}=\frac{\theta}{\theta-1}$.

${ }^{19}$ Using Euler's homogeneous function theorem that $F_{l} l+F_{k} k=\nu F(k, l)$ then the result follows from substitution of factor prices $A F_{l}(1-\zeta) l+A F_{k}(1-\zeta) k$.
} 
the benefit of an extra product to the consumer, and the profit incentive of an entrant. Rearranging (16) shows that firm output varies positively, and more than proportionately, with current operating profits

$$
y=\frac{d+\nu(1-\zeta) \phi}{1-(1-\zeta) \nu}
$$

Proposition 1. Aggregate output can be expressed as a function of inputs and measured TFP.

$$
Y=\operatorname{TFP} F(K, L)^{\frac{1}{\nu}}
$$

where measured TFP depends on endogenous d

$$
\mathrm{TFP} \equiv\left(\frac{A}{d+\phi}\right)^{\frac{1}{\nu}}(1-(1-\zeta) \nu)^{\frac{1}{\nu}-1}[(1-\zeta) \nu \phi+d]
$$

\section{Proof. See Appendix D}

The inclusion of operating profits in measured TFP leads to endogenous measured TFP dynamics when profits are not instantaneously zero. ${ }^{20}$ If profits were instantaneously zero, then (19) would be fixed, which is why with instantaneous entry endogenous productivity fluctuations do not arise. As per firm output and operating profits are in a one-one mapping from (17), we shall interpret this endogenous TFP movement through changes in $y$ (primal approach), so-called excess capacity utilization. ${ }^{21}$ The relationship is convex which relates to the U-shaped AC curve. ${ }^{22}$

$$
\mathrm{TFP}_{d}=A^{\frac{1}{\nu}}(1-(1-\zeta) \nu)^{\frac{1}{\nu}-1}(1-\nu)\left[\frac{\zeta \nu \phi}{(1-\nu)}-d\right]
$$

As Jaimovich and Floetotto 2008 have argued, and Etro and Colciago 2010 acknowledge,

20 The result generalizes Jaimovich and Floetotto 2008, eq. 17 appendix. They acknowledge the bias it creates, but their focus is on endogenous markup bias. They have constant returns to scale $\nu=1$ which gives $\frac{Y}{F(K, L)}=A\left[1-\zeta \frac{\phi}{d+\phi}\right]=A(1-\zeta)\left[1+\frac{\zeta}{1-\zeta} \frac{d}{d+\phi}\right]$.

21 This scale-adjusted TFP definition $\left(Y / F^{\frac{1}{\nu}}\right)$, where the denominator is normalized to make the production function hod-1 as opposed to hod- $\nu$, is widely used with increasing returns and instantaneous entry (Da-Rocha, Tavares, and Restuccia 2017; Barseghyan and DiCecio 2011). Basu and Fernald 2001 give a detailed discussion of scale adjusted productivity, whilst Harrison 1994 and Feenstra 2003 derive a similar measure for regression analysis.

${ }^{22}$ Under $d=0$ productivity is increasing in profits reflecting production to the left-hand side of the minimum AC. 
the standard Solow residual is an upward biased measure of technology in the presence of endogenous markups that respond to entry and exit. In this paper we have a fixed markup so that bias is not present, but we explore the bias that arises due to short-run non-zero profits and resulting excess capacity utilization. ${ }^{23}$ Unlike endogenous markup biases that are present in both the short-run and the long-run because of changes in the slope of demand curves, capacity utilization biases are present only in the short-run because it delays the shift in the demand curve, which will move once entry and thus business stealing take place to arbitrage profits to zero.

\subsection{Firm Entry}

The number of firms at time $t$ is determined by two conditions: an endogenous entry cost (congestion effect) and an arbitrage condition that equates entry cost with incumbency profits (value of an incumbent). The congestion effect states that entry cost $q \in \mathbb{R}$ increases with the flow of entrants $\dot{N}$ in $t$.

$$
q=\gamma \dot{N}, \quad \gamma \in(0, \infty)
$$

The process is symmetric, a prospective firm pays $q(t)$ to enter at $t$ and $-q(s)$ to exit at $s>t{ }^{24} \dot{N}$ is the change in the stock of firms and represents net business formation; we define this as 'entry'. $\gamma$ are dynamic barriers to entry that reflect the sensitivity of entry costs to net entry. They can be interpreted as regulatory costs. When a firm wishes to setup it must access a resource that is in inelastic supply (like a government office), therefore if more firms are entering this process is slower and entry costs are higher. Its bounds capture the limiting cases of entry: $\gamma \rightarrow 0$ implies instantaneous free entry because the entry cost is small so the outcome is similar to the static case, and $\gamma \rightarrow \infty$ implies fixed number of firms because the entry cost is so high that it prohibits entry. ${ }^{25}$

\footnotetext{
${ }^{23}$ This effect is present in Bilbiie, Ghironi, and Melitz 2012 but is not developed.

${ }^{24}$ If there is exit $\dot{N}<0$, so $q<0$ and $-q>0$ this means an incumbent pays a dismantling fee to exit, for example redundancy payments or legal fees. Sunk cost symmetry is not a necessary feature of the model. It eases exposition as we only focus on deterministic shocks in a single direction. To generalize the process for asymmetric costs, $\gamma$ must differ for entry and exit.

${ }^{25}$ The congestion effect assumption has been used in the industrial organization literature (S. Das and S. P. Das 1997), and it is growing in usage in macroeconomics (Lewis 2009, Bergin and Lin 2012
} 
The second condition is entry arbitrage which binds the number of firms. It states that the gain from entry equals return from investing the cost of entry at the market rate.

$$
r(C, K, N) q(N)=d(C, K, N)+\dot{q}(N)
$$

This arbitrage equation follows from stating that the value of a firm is equal to present discounted value of future profits as in Bilbiie, Ghironi, and Melitz 2012 and Datta and Dixon 2002. Then free entry condition that the net present value of the firm is equal to the sunk cost then gives $(22) \cdot{ }^{26}$

The two conditions form a dynamical system in number of firms and cost of entry $\{N, q\}$ which reduces to a second-order nonlinear ODE in number of firms

$$
\gamma \ddot{N}-\gamma r(N) \dot{N}+d(N)=0
$$

To interpret this second-order ODE consider that if profits are high, then to maintain equilibrium the speed of net business formation $\dot{N}$ is high. This causes higher entry costs, thus discouraging future entry, so net business formation decelerates $\ddot{N}<0$ to maintain equilibrium. By defining entry as the net change in stock of firms $(E(t) \equiv \dot{N})$, this second-order ODE is separable into two first-order ODEs. Hence our model of industry dynamics, which determines the number of firms, is defined by two ODEs, and requires two boundary conditions for uniqueness

$$
\begin{aligned}
\dot{N} & =E \\
\dot{E} & =-\frac{d}{\gamma}+r E, \quad \gamma>0 \\
\lim _{t \rightarrow \infty} N(t) q(t) u_{C}(t) e^{-\rho t} & =0 \\
N(0) & =N_{0}
\end{aligned}
$$

The endogenous sunk cost causes a non-instantaneous adjustment path to steady state, which provides an analytical framework to understand short-run dynamics. It creates

\footnotetext{
Berentsen and Waller 2015).

${ }^{26}$ In the case of exit profits are negative $d<0$, firms exit $\dot{N}<0$, implying high exit costs, which decelerates exit $\ddot{N}<0$.
} 
an incentive to delay entry as congestion effects will fall in the future. Contrarily, take an exogenous entry cost $q=\gamma \geq 0$. The second-order ODE becomes static $d=r \gamma$ and entry will adjust instantaneously to equate net present value of operating profits with the opportunity cost (sunk cost invested at market rate).

\subsubsection{Entry Costs in Aggregate}

To understand firm dynamics in general equilibrium, the aggregate investment in firms must be accounted for in terms of aggregate output (a market clearing condition). Integrating the sunk cost of entry across all entrants in a period gives the aggregate cost of entry in terms of output

$$
Z=\gamma \int_{0}^{E} i d i=\gamma \frac{E^{2}}{2}
$$

This will appear as a quadratic adjustment cost in entry in the aggregate equation of motion for capital when we substitute out aggregate profits. Aggregate profits are all firms' operating profits (16) less the aggregate sunk cost.

$$
D=N d-Z
$$

\subsection{Aggregate Resource Constraint}

Given our expression for aggregate profits (29), we can substitute this into the household resource constraint (2) to yield $C+\dot{K}+Z=r K+w L+N d$ which states expenditure equates to income. Expenditure is divided between consumption, investment in capital, and adjustment costs paid to setup firms $Z$. Income is earned from capital, labour and operating profits from firm ownership. Substituting factor prices and profits into the right-hand side gives aggregate output $Y$ and rearranging gives the aggregate equation of motion for capital

$$
\dot{K}=Y-C-\gamma \frac{E^{2}}{2}
$$




\section{Equilibrium}

\subsection{Market (decentralised) Equilibrium}

Definition 1 (Market Equilibrium). The market equilibrium determines prices, consumption, entry and labour given the current capital stock and number of firms. Labour is defined implicitly as $L(C, K, N)$ through labour supply (household intratemporal condition) (4) and labour demand (14), so by substitution the model reduces to a dynamical system of four ordinary differential equations (ODEs) (3), (25), (30), (24) in four variables $(C, E, K, N)$. Additionally there are two initial conditions (5, 27) and two transversality conditions (6, 26) which provide the four boundary conditions necessary for a solution to the four dimensional dynamical system.

Appendix A outlines all the model equilibrium conditions recursively and reduces them to a 4 d dynamical system. ${ }^{27}$

Proposition 2 (Instantaneous Entry Reduced Form). If dynamic barriers to entry are zero $(\gamma=0)$, entry adjusts instantaneously, profits are always zero, and output per firm is fixed

$$
y(t)=\frac{\nu(1-\zeta) \phi}{1-(1-\zeta) \nu}, \quad \forall t \in(0, \infty)
$$

The model reduces to a $2 d$ system with the dynamic properties of a Ramsey Cass Koopmans model with endogenous labour.

Proof. If barriers to entry are zero $\gamma=0$, then (23) implies $d=0$, which from (17) gives $y$. The equilibrium conditions reduce to two differential equations $\dot{K}, \dot{C}$, where the quadratic sunk entry cost in $\dot{K}$ is zero.

\subsection{Planner Allocation}

Unlike the market (decentralised) equilibrium, where the household maximizes utility (1) subject to a budget constraint (2) that takes aggregate profits (dividends and entry costs)

\footnotetext{
${ }^{27}$ Savagar 2019 shows that this decentralised nonparametric equilibrium has a unique steady-state and saddle-path dynamics. He provides conditions for the more general case of endogenous markups, and shows that the conditions are always satisfied in the exogenous (fixed) markup case. In this paper we provide a proof for the parametric case.
} 
and factor prices as given by the market, the planner maximizes utility (1) subject to the aggregate resource constraint (30) and boundary conditions with control over $C, L, E$ and constrained by the evolution of state variables $K, N{ }^{28}$

Definition 2 (Planner Allocation). A planner allocation consists of paths of consumption, entry, capital and firms $[C(t), E(t), K(t), N(t)]_{t=0}^{\infty}$ such that the social planner maximizes aggregate utility (1) subject to the aggregate resource constraint (30) and boundary conditions.

The formal planner maximization problem, optimization conditions and corresponding $4 \mathrm{~d}$ dynamical system with boundary conditions are specified in Appendix B. ${ }^{29}$

Proposition 3. The decentralised market equilibrium is equivalent to the social planner's solution in the special case of perfect competition $\zeta=0$.

Proof. Appendix B.2.

\subsection{Capacity Utilization}

The microproduction literature refers to capacity utilization as temporary or subequilibrium changes in production that arise due to quasi-fixity of inputs. Input quasi-fixity causes disparities between shadow prices and actual prices that are captured by positive profit, which subsequently cause adjustment of quasi-fixed inputs. In our model capital per firm is quasi-fixed because both capital and firms do not respond at time 0 to shocks.

Definition 3. Capacity utilization is the ratio of the market allocation of production to planner allocation of production (which exists under perfect competition). Excess capacity is the residual.

$$
\begin{aligned}
& C U(t) \equiv \frac{y(t)}{y^{\mathrm{PA}}} \\
& E C(t) \equiv 1-C U(t)
\end{aligned}
$$

\footnotetext{
${ }^{28}$ The aggregate resource constraint follows from the household budget constraint when we consider that the planner has control over investment in firms and therefore aggregate profits $D$ which consist of operating profits and entry costs as well as factor prices $w, r$. See Section 1.4.

${ }^{29}$ Brito and Dixon 2013 present a direct proof of saddle stability and steady-state uniqueness in this planner version of the model.
} 


\subsection{Labour Market}

Given wage $w(L, K, N)$ at market equilibrium (14), the intratemporal condition (4) defines optimal labour supply statically as a function of consumption, capital and number of firms $L(C, K, N)$

$$
A F_{l}(k, l)(1-\zeta)=-\frac{u_{L}(L)}{u_{C}(C)}
$$

The intratemporal condition shows that the marginal rate of substitution between consumption and labour equates to the wage. From the implicit function theorem, we can determine that labour supply increases in capital $\left(L_{K}>0\right)$ and number of firms $\left(L_{N}>0\right)$ and decreases in consumption $\left(L_{C}<0\right) .{ }^{30}$ Labour is decreasing in consumption because a rise in consumption causes the marginal utility of consumption to fall (consumption is a normal good). Therefore marginal disutility of labour must decrease to maintain the marginal rate of substitution, hence labour decreases which reduces disutility. Capital causes an increase in the labour supply through an increase in the marginal product of labour and hence real wage. The firm entry effect is more novel:

Proposition 4. Firm entry increases labour supply $L_{N}>0$.

\section{Proof. Appendix C}

The result arises because production has increasing marginal costs $\nu \in(0,1)$. Entry increases labour because an additional firm decreases employment per firm and therefore raises the marginal product of labour and consequently wage. This dominates other general equilibrium channels. Additionally, with constant marginal costs and imperfect competition $\left(\zeta>0\right.$ necessary for existence), entry does not affect labour supply $\left.L_{N}\right|^{\nu=1}=$ 0. With constant returns the capital-labour ratio (hence MPL) is unaffected by entry, so labour supply is unresponsive. ${ }^{31}$

\footnotetext{
${ }^{30}$ See Appendix C for derivations.

${ }^{31}$ These nontrivial entry effects on labour follow empirical evidence (Haltiwanger, Jarmin, and Miranda 2013) that firm births contribute substantially to net job creation. Most papers on firm entry disregard this channel by assuming constant marginal costs $(\nu=1)$ and no perfect competition $(\zeta=0)$.
} 


\subsection{Business Stealing}

Slow firm entry means that profits and output per firm are not instantaneously fixed, unlike the instantaneous entry case of Proposition 2. Instead they vary in the short-run, eventually reaching a zero profit, fixed output per firm level in the long run. Given the general equilibrium behaviour of the labour market, we can understand the general model predictions for output per firm (intensive margin) and therefore operating profits over the transitioning period.

Proposition 5. Output per firm and operating profit are decreasing in consumption $\left(y_{C}<\right.$ $0)$, increasing in capital $\left(y_{K}>0\right)$ and decreasing in number of firms $\left(y_{N}<0\right)$.

\section{Proof. Appendix D}

Entry always decreases incumbents' intensive margin, which is equivalent to decreasing operating profits by relationship (17). ${ }^{32}$ This implies that business stealing prevails at the intensive margin, despite the counteracting labour supply effect of Proposition $4 .{ }^{33}$ The effect of an entrant on aggregate output (extensive margin) is ambiguous. Whether entry increases, decreases or maximizes aggregate output depends on the trade-off between the negative business stealing effect (Proposition 5) and the positive labour supply effect (Proposition 4): $Y_{N}=y+N y_{N}$. An entrant contributes its own output $y$, but also has a negative effect on the intensive margin of all $N$ incumbents. This negative aggregate business stealing effect is given by:

$$
N y_{N}=-\nu A N^{-\nu} F(K, L)+A N^{1-\nu} F_{L} L_{N}<0
$$

The first term is the amount of resources the entrant steals from incumbents (when, ceteris paribus, increasing $N$ divides inputs $K, L$ among more firms). The second effect is a labour supply increase that exists because of increasing marginal costs (Proposition 4). The entrant's own contribution $y$ can be written as profits plus variable costs $y=$

\footnotetext{
${ }^{32}$ This would not be the case with love-of-variety where aggregate demand externalities play a countervailing role (Acemoglu 2009, Ch. 12; Vives 1999, Ch. 6), such that profits can increase in entry.

${ }^{33}$ Mankiw and Whinston 1986 state "[business stealing] exists when the equilibrium strategic response of existing firms to new entry results in their having a lower volume of sales-that is, when a new entrant "steals business" from incumbent firms. Put differently, a business-stealing effect is present if the equilibrium output per firm declines as the number of firms grows."
} 
$d+(1-\zeta) \nu A N^{-\nu} F(K, L)$. From (33) the amount it steals is $\nu A N^{-\nu} F(K, L)$ but in order to cover the new overhead $\phi$ that the entrant has incurred it resells the stolen output with a markup $1-\zeta$. The entrant steals $\nu A N^{-\nu} F(K, L)$ but only adds $(1-\zeta) \nu A N^{-\nu} F(K, L)$.

The deadweight loss from the transfer in business is $-\zeta \nu A N^{-\nu} F(K, L)$ giving:

$$
Y_{N}=d-\zeta \nu A N^{-\nu} F(K, L)+A N^{1-\nu} F_{L} L_{N}
$$

Therefore the aggregate entry effect is the entrant's profit, less the deadweight loss from business stealing, plus the general equilibrium labour supply effect from higher wages. ${ }^{34}$ By trading off the opposing effects of entry on business stealing and labour efficiency, an optimal $\left(Y_{N}=0\right)$ amount of entry can be achieved. ${ }^{35}$

\section{Steady State}

In steady state aggregate output equals consumption $Y^{*}=C^{*}$ (as zero depreciation); net entry is zero $E^{*}=0$; capital returns equal the discount factor $r^{*}=\rho$ and operating profits are zero $d^{*}=0$. See Appendix A for full steady state conditions.

Proposition 6. In steady-state, the market equilibrium output per firm and TFP are

$$
\begin{aligned}
y^{*} & =\frac{\nu(1-\zeta) \phi}{1-(1-\zeta) \nu} \\
\mathrm{TFP}^{*} & =A^{\frac{1}{\nu}} \nu(1-\zeta)\left(\frac{1-\nu(1-\zeta)}{\phi}\right)^{\frac{1-\nu}{\nu}}
\end{aligned}
$$

Proof. See appendix A.2

Steady-state output per firm (35) is increasing in both fixed cost $\phi$ and returns to scale $\nu$ and is decreasing in market power $\zeta$. Increasing market power raises marginal

\footnotetext{
${ }^{34}$ The expression generalizes Mankiw and Whinston 1986, eq. 2 to the aggregate economy with endogenous labour. They focus on a partial equilibrium industry setting with constant marginal costs. From (16) rewriting the result as $Y_{N}=(1-\nu) A F-\phi+A N^{1-\nu} F_{L} L_{N}$ shows that with constant returns (and strict imperfect competition for existence $\zeta>0$ ) the first and third terms are zero, so an entrant always decreases aggregate output $\left.Y_{N}\right|^{\nu=1}=-\phi$ by the overhead cost it incurs.

${ }^{35} \mathrm{By}(34)$, steady-state aggregate output (which equals consumption with no depreciation) is maximized under a specific parameterization of $(\nu, \zeta)$ implying a trade-off for policy to affect, and mentioned in the next section. This extends Etro and Colciago 2010 discussion of excessive entry ('dynamic inefficiency') in a similar model with endogenous markups, but without the offsetting labour supply effect from increasing marginal costs, which is what makes an optimal level attainable here in the absence of endogenous markups.
} 
revenue products of inputs, so less needs to be produced in order to cover fixed costs and attain zero profits. A perfect competition $(\zeta=0)$ steady-state output exists because firms face a fixed cost and increasing marginal cost which leads to U-shaped average cost. Steady state measured TFP is decreasing in market power $\zeta$ because it allows firms to suppress output more, so they exploit fixed cost returns to scale less.

Proposition 7. In steady-state, the planner allocation output per firm and TFP are

$$
\begin{aligned}
y^{\mathrm{PA}} & =\frac{\nu \phi}{1-\nu} \\
\mathrm{TFP}^{\mathrm{PA}} & =A^{\frac{1}{\nu}} \nu\left(\frac{1-\nu}{\phi}\right)^{\frac{1-\nu}{\nu}}
\end{aligned}
$$

Proof. See appendix A.2

Along the path to steady-state, whilst output per firm may be greater or less than (37), there will be no first-order reduction in productivity.

Corollary 1. The steady-state planner (perfectly competitive) level of output maximizes TFP.

\section{Proof. See appendix D}

If firms were to produce the efficient scale (37) under imperfect competition they would earn positive profits $d^{\mathrm{PA}}=\zeta y^{\mathrm{PA}}$. Given these positive profits, firms continue to enter to arbitrage them to zero, and the resulting situation is smaller firms each with excess capacity. A lump-sum tax on firm profits (rebated as a subsidy to output) equal to $\zeta y^{P A}$ would prevent further entry and ensure optimality. ${ }^{36}$

In steady state firms competing under monopolistic competition $\zeta \in(0,1)$ have excess capacity.

$$
C U^{*}=\frac{y^{*}}{y^{\mathrm{PA}}}=1-\frac{\zeta}{1-(1-\zeta) \nu}<1, \quad \text { where, } E C^{*}=\frac{\zeta}{1-(1-\zeta) \nu}
$$

\footnotetext{
${ }^{36}$ Bilbiie, Ghironi, and Melitz 2019; Etro 2018 study the normative properties of models with entry and product variety extensively (including variety effects and endogenous markups from different preference setups). Importantly BGM emphasize the size of dynamic effects. Our analysis of static outcomes is designed to aid understanding of our main result regarding endogenous productivity.
} 
Under perfect competition $\zeta=0$, there is full capacity $C U^{*}=1$ and no excess capacity $E C^{*}=0$. When there is excess capacity in steady-state this implies firms have locally increasing returns to scale, as they do no fully utilize their overhead cost. They produce below their most efficient scale on the left-hand side of their U-shaped average cost curve.

Lemma 1. In excess capacity steady state $\zeta \in(0,1)$, TFP is increasing in output per firm:

$$
\left.\operatorname{TFP}_{y}\right|^{*}=\zeta\left(\frac{A(1-(1-\zeta) \nu)}{\phi}\right)^{\frac{1}{\nu}}>0
$$

These first-order effects do not exist at the full capacity, perfectly competitive scale, $\zeta=$ $\left.0 \Longrightarrow \mathrm{TFP}_{y}\right|^{*}=0$.

Proof. Evaluate (106) at steady state (35).

Lemma 1 implies that there will be first-order effects of output on productivity around steady-state except for the special case of $\zeta=0$ (the planner problem). The intuition for these results (efficiency, excess capacity, and increasing returns) follows from Figure 3 which shows the U-shaped cost curves facing an incumbent firm. The long-run cost function (LRAC) plots minimum cost for each level of output, given labour and capital can adjust, whereas the short-run cost curve (SRAC) plots minimum cost given only labour can adjust, capital is fixed at the cost-minimizing capital for that output. $y^{*}$ is less than $y^{\mathrm{PA}}$ which represents excess capacity, and $y^{\mathrm{PA}}$ minimizes long-run average costs which represents full capacity, minimum efficient scale. The slope of the short-run cost function equals the slope of the long-run cost function at $y^{*}$, and it is downward sloping which represents increasing returns to scale because costs fall with output. The tangent at $y^{\mathrm{PA}}$ is horizontal which implies locally constant returns to scale. 


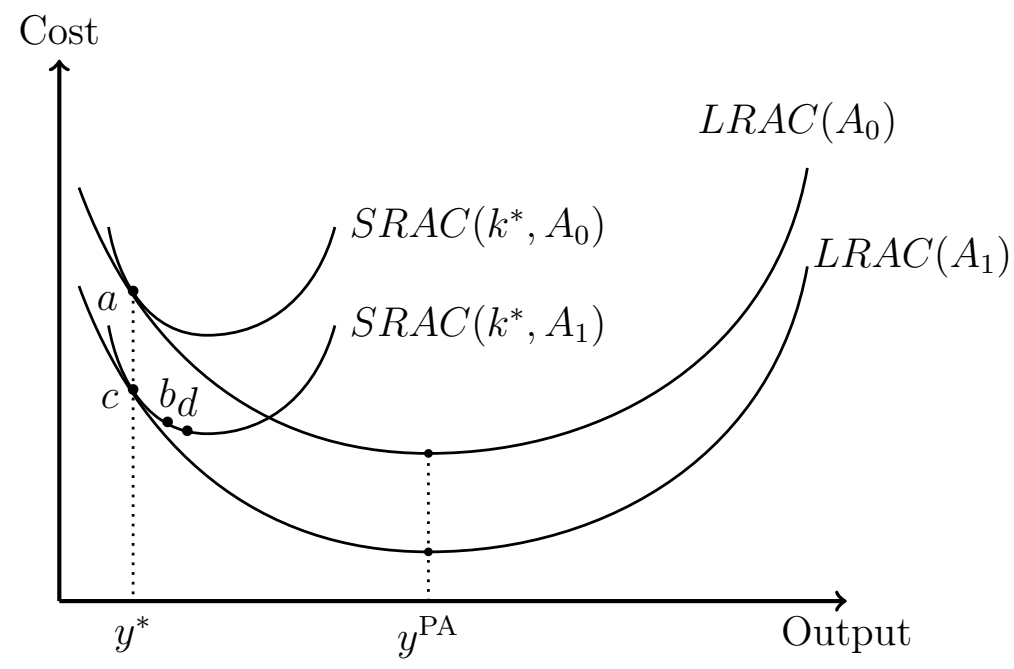

Figure 3: Long-run and short-run average cost curves

\section{Technology and Capacity Utilization}

In this section we analyze the effect of a technology shock on capacity utilization and productivity. We begin by giving a graphical description, and then we formalize this intuition in the model.

\subsection{Graphical Explanation}

Figure 3 plots the effect of a positive technology shock on an incumbent firms' costs, and consequently productivity response. The economy begins in steady state at $a$ with technology $A_{0}$. A technology improvement to $A_{1}$ instantly shifts the long-run and shortrun cost curves downwards, but capital per firm remains at its initial steady state level $k^{*}$ in the short-run whereas labour per firm $l\left(0, A_{1}\right)$ can adjust. ${ }^{37}$ Therefore the SRAC curve cannot move along its LRAC envelope (as this requires a change in the firm's capital $k$ ), but production can vary along the given SR curve as labour changes instantaneously. A short-run capacity utilization mechanism arises as $l$ changes causing a movement along the SRAC curve to a position like $d$. In the long run, entry occurs so that $k$ and $l$ adjust

\footnotetext{
${ }^{37}$ If neither $k$ nor $l$ adjust, there is still a scale effect change to $b$ which is what we control for by making the denominator homogeneous of degree 1 in the measured TFP definition. That is, with fixed $k, l$ there would be some movement of the SRAC along the LRAC, due to scale effects since $\nu<1$ but we adjust for this, see footnote 21 .
} 
to return the incumbent to producing its fixed long-run level $y^{*}$ at lower cost point $c$. The true change in costs, thus productivity, in the long-run is $a$ to $c$. But in the short-run there will be a temporary movement to $d$ as other firms adjust. This short-run effect is capacity utilization.

Under perfect competition or instantaneous entry the capacity utilization effect will not arise. Under perfect competition, production is always at minimum average cost, so the level shift is captured accurately because the tangent at minimum is horizontal implying no additional variation in costs. Under instantaneous entry, then capital per firm is no longer quasi-fixed. In this situation, profits are instantaneously zero as the downward shift in cost curve is accompanied by an outward shift in demand (inward shift in inverse demand) to arbitrage profits. The technology shock is only felt through factor demands and the immediate entry means the number of firms immediately jumps to its new steady state. Therefore the extensive margin of aggregate output $Y^{*}=N^{*} y^{*}$ adjusts immediately whereas the intensive margin $y^{*}$ is unchanged (output per firm never deviates from $\left.y^{*}\right)$.

\subsection{Model Derivation}

In the long-run, free-entry, zero-profit steady state, a firm only produces enough to cover its fixed cost $\phi$, so a positive technology shock allows a firm to combine fewer inputs to cover $\phi$. Therefore the intensive margin is fixed, but the extensive margin will adjust. That is, technology does not affect the average firm size, but it will affect the number of firms and thus aggregate output. ${ }^{38}$

Proposition 8 (Long-run Effect of Technology). Long-run firm size, efficient scale, and therefore capacity utilization are independent of technology

$$
y_{A}^{*}=0, \quad y_{A}^{\mathrm{PA}}=0, \quad C U_{A}^{*}=0
$$

\footnotetext{
${ }^{38}$ Constant average firm size arises because fixed costs are unaffected by technology. Generalizing production to $y=A F(k, l)-A^{\kappa} \phi$ with $\kappa \in(-1,1)$ would give $y^{*}=A^{\kappa} \frac{\nu(1-\zeta) \phi}{1-(1-\zeta) \nu}$. Therefore $\kappa$ determines whether firm size increases or decreases in response to $A$. We focus on $\kappa=0$ as our main interest is transitional dynamics, so having $y^{*}$ irresponsive to $A$ focusses on short-run variations in $y$. Under the $\kappa \in(-1,1)$ setup, our results remain. They depend on differences between short-run and long-run changes in capacity, rather than only the short-run, but these are complex to track.
} 
Proof. Take derivatives of (35), (37), (39).

Since long-run output per firm (intensive margin) is fixed in response to a technology shock, long-run aggregate output (extensive margin) depends on the number of firms response to technology through $Y^{*}=N^{*} y^{*}$, hence:

$$
Y_{A}^{*}=C_{A}^{*}=N_{A}^{*} y^{*}
$$

To maintain long-run fixed output per firm implies inputs adjust to accommodate technology.

Corollary 2. Labour per firm always decreases, whereas the effect on capital per firm is is ambiguous.

$$
\begin{aligned}
& l_{A}^{*}<0 \\
& k_{A}^{*} \lesseqgtr 0 \Longleftrightarrow \frac{F_{l}}{F_{k l}} \gtreqless \frac{(1-\zeta) \phi}{\rho(1-(1-\zeta) \nu)}
\end{aligned}
$$

Proof. Appendix D

The relative effect of labour on production to labour on marginal product of capital determines capital per firm response to a technology shock. ${ }^{39}$

Theorem 1 (Endogenous Productivity). When firms have market power and entry is slow to adjust, a technology shock causes endogenous fluctuations in measured TFP as incumbents vary capacity utilization. The necessary and jointly sufficient conditions are

1. Imperfect competition $\zeta \in(0,1)$ ensures there are locally increasing returns to scale.

2. Dynamic barriers to entry $\gamma>0$ ensure slow firm entry so there are short-run variations in incumbent's capacity utilization.

\footnotetext{
${ }^{39}$ In our Cobb-Douglas production, isoelastic utility example $k_{A}^{*}=0$. Therefore fixity of $y^{*}$ after an increase in technology, follows solely from a decrease in $l^{*}$. Furthermore with logarithmic consumption utility long-run aggregate labour supply is irresponsive to technology $L_{A}^{*}=0$, so firm entry is solely responsible for the fall in labour per firm $l_{A}^{*}=-\frac{L^{*}}{N_{A}^{*}}$.
} 
Proof. At $t$ a change in technology will affect measured productivity directly and through a change in capacity utilization ${ }^{40}$

$$
\operatorname{TFP}_{A}(t)=\frac{\partial \operatorname{TFP}(t)}{\partial A}+\operatorname{TFP}_{y}(t) y_{A}(t)
$$

In the long-run there is no capacity utilization effect $y_{A}^{*}=0$ (Proposition 8). Therefore only the first term is present. However, in the short run, beginning at steady state, both the long-run and capacity utilization effects remain ${ }^{41}$

$$
\left.\operatorname{TFP}_{A}(0)\right|^{*}=\operatorname{TFP}_{A}^{*}+\left.\operatorname{TFP}_{y}^{*} y_{A}(0)\right|^{*}
$$

The necessary conditions ensure the capacity utilization term $\left.\operatorname{TFP}_{y}^{*} y_{A}(0)\right|^{*}$ is nonzero. Condition 1 follows from Lemma 1. Condition 2 follows from Proposition 2.

We sketch the intuition of the main result in figure 4. Equation (44) shows that the short-run effect of a technology shock on measured productivity consists of the long-run effect plus short-run excess capacity utilization. ${ }^{42}$ The simple direct effect $\mathrm{TFP}_{A}^{*}$ captures that improved technology shifts the production function which increases measured productivity both in the short run and the long run. The excess capacity utilization effect $\left.\mathrm{TFP}_{y}^{*} y_{A}(0)\right|^{*}$ captures the short-run capacity response $y_{A}(0)$ interacted with returns to scale $\operatorname{TFP}_{y}(t)$.

\footnotetext{
${ }^{40}$ Analogously the result can be interpreted through profits $d_{A}=y_{A}(1-(1-\zeta) \nu)$, and $\mathrm{TFP}_{A}=$ $\frac{\partial \mathrm{TFP}}{\partial A}+\mathrm{TFP}_{d} d_{A}$.

${ }^{{ }^{A}}$ Note the limit of the derivative is the derivative of their $\operatorname{limits}\left(\right.$ e.g. $\lim _{t \rightarrow \infty} N_{A}(t)=N_{A}^{*}$ ), see Caputo 2005, p. 476. So in the limit the response of state variables is the same as the response of their steady state value.

${ }^{42}$ The result is still present with constant returns $\nu=1$. The returns to scale component is simpler $\mathrm{TFP}_{y}^{*}=\zeta \nu$ so $\left.\operatorname{TFP}_{A}(0)\right|^{*}=\mathrm{TFP}_{A}^{*}+\left.\zeta A y_{A}(0)\right|^{*}, \quad \zeta>0$. But perfect competition outcomes do not exist in this setting, so there is no efficiency benchmark to measure excess capacity against.
} 


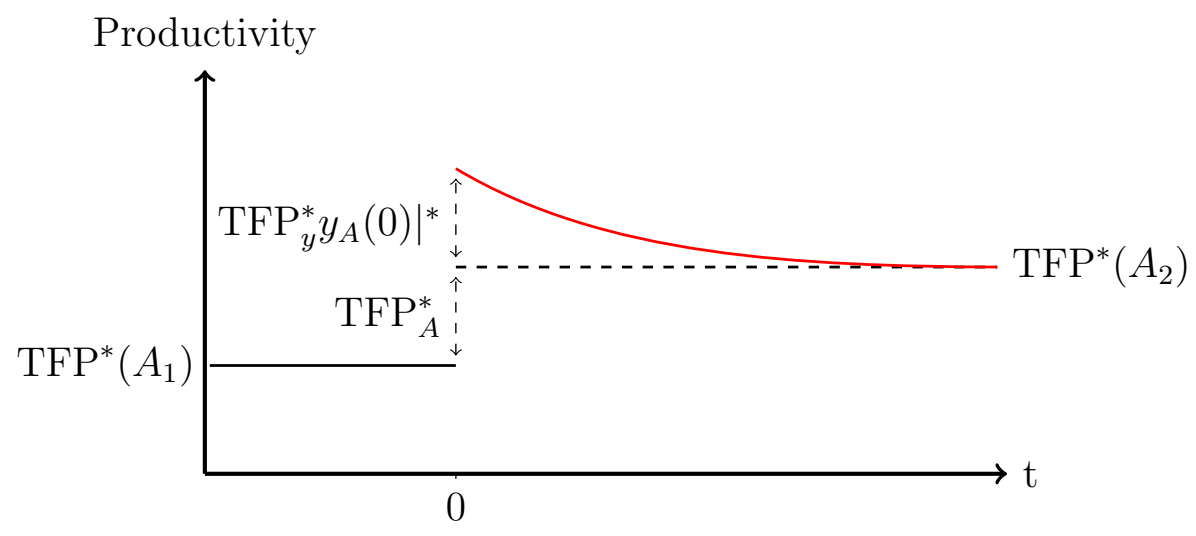

Figure 4: One-time Exogenous Technology Increase $A_{1} \rightarrow A_{2}$

Corollary 3. Given firm response $\left.y_{A}(0)\right|^{*}$, greater imperfect competition implies greater excess capacity, greater returns to scale, and greater productivity fluctuations.

Proof. Increasing imperfect competition $\zeta$, decreases (39), increases (40), and consequently increases $\left|\operatorname{TFP}_{y}^{*} y_{A}(0)\right|^{*} \mid$.

From figure 3, Corollary 3 formalizes that a less competitive firm produces further from minimum LRAC (more excess capacity), faces a steeper slope (stronger returns to scale) and thus a given change in output affects costs more, hence productivity fluctuates more.

Figure 4 shows the case of excess capacity utilization $\left.\left.\left(y_{A}(0)\right)\right|^{*}>0\right)$ creating an overshooting effect. However, a positive technology shock can create capacity widening $\left(\left.y_{A}(0)\right|^{*}<0\right)$ and undershooting if technological advancement strongly decreases labour supply due to a strong income effect. From (44):

$$
\left.\left.y_{A}(0)\right|^{*} \gtreqless 0 \Longrightarrow \operatorname{TFP}_{A}(0)\right|^{*} \gtreqless \operatorname{TFP}_{A}^{*}
$$

In general output per firm response is ${ }^{43}$

$$
y_{A}(t)=\frac{\partial y}{\partial A}+y_{L} \frac{\partial L}{\partial A}+y_{N} N_{A}+y_{K} K_{A}+y_{C} C_{A}
$$

where each output response coefficient internalizes the labour effect, as given in Proposition 5. Assuming the primitive variables are monotonically increasing following an

\footnotetext{
${ }^{43}$ Which follows from $y_{A}=\frac{\partial y}{\partial A}+\frac{\partial y}{\partial N} N_{A}+\frac{\partial y}{\partial K} K_{A}+y_{L} L_{A}$ and substitution of $L_{A}=\frac{\partial L}{\partial A}+L_{N} N_{A}+$ $L_{K} K_{A}+L_{C} C_{A}$.
} 
increase in technology $\left(N_{A}, K_{A}, C_{A}>0\right)$, then technology has a positive direct effect $\frac{\partial y}{\partial A}>0$, a positive MPL effect (substitution effect) $y_{L} \frac{\partial L}{\partial A}>0$, a positive effect from capital accumulation $y_{K}=\frac{\partial y}{\partial K}+y_{L} L_{K}>0$, a negative business stealing effect from entry $y_{N}=\frac{\partial y}{\partial N}+y_{L} L_{N}<0$ and a negative effect from consumption crowding out (income effect) $y_{C}=y_{L} L_{C}<0$. Proposition 8 implies that the positive and negative effects on output per firm in (45) cancel out in the long-run ensuring $y_{A}^{*}=0 .{ }^{44}$ However in the short run, absence of negative business stealing effect may lead to overshooting.

Proposition 9. A necessary and sufficient condition for overshooting is that the direct output effect and labour substitution effect collectively dominate the labour income effect. A sufficient condition is that the substitution effect dominates the income effect.

Proof. If capital and number of firms are quasi-fixed (state variables), they do not respond to the shock in the short-run. Therefore the output response (45) depends on the direct effect, and labour's immediate jump which consists of positive substitution and negative income effect.

$$
\left.y_{A}(0)\right|^{*}=\frac{\partial y}{\partial A}+y_{L} L_{A}(0)=\frac{\partial y}{\partial A}+y_{L}\left(\frac{\partial L}{\partial A}+L_{C} C_{A}(0)\right)
$$

The necessary and sufficient condition is

$$
\frac{\partial y}{\partial A}+y_{L} \frac{\partial L}{\partial A}>-y_{L} L_{C} C_{A}(0)
$$

and the sufficient condition is $\frac{\partial L}{\partial A}>-L_{C} C_{A}(0)$ implying $L_{A}(0)>0$.

Consequently if technological advancement initially increases labour supply, then measured productivity overshoots its long-run level. Through profits, we can also understand the dual-interpretation of this: if the initial rise in $A$ is offset by the fall in $L(0)$, then through (16) operating profits fall, which is analagous to capacity widening through (17).

\footnotetext{
${ }^{44}$ If $N_{A}^{*}, K_{A}^{*}, C_{A}^{*}>0$, then a combination of the negative business stealing $\left(y_{N}<0\right)$ and income effects $\left(y_{C}<0\right)$ reduce output after any initial overshooting. In a logarithmic utility case, income and substitution effects exactly equate so $L_{A}^{*}=0$ and business stealing is solely responsible for reducing output per firm.
} 


\section{Quantitative Exercise}

In this section we parameterize and simulate the model in order to illustrate our main theoretical result. As in the baseline RBC model we assume isoelastic utility and CobbDouglas production.

$$
\begin{gathered}
U(C, L)=\frac{C^{1-\sigma}-1}{1-\sigma}-\xi \frac{L^{1+\eta}}{1+\eta} \\
F(k, l)=k^{\alpha} l^{\beta}=K^{\alpha} L^{\beta} N^{-(\alpha+\beta)}
\end{gathered}
$$

where $\alpha$ and $\beta$ are capital and labour shares. $\sigma$ is a curvature parameter, and $\eta \geq 0$ is inverse Frisch elasticity. ${ }^{45}$

\subsection{Steady State and Calibration}

We present the full parametric steady state conditions in Appendix E.1. We know in general from nonparametric steady-state outcomes (Proposition 8) that output per firm is independent of technology. Additionally in the parametric Cobb-Douglas case, the ratio $\frac{F_{l}}{F_{k l}}$ implies capital per firm is independent of technology $k_{A}^{*}=0$ (Corollary 2). ${ }^{46}$ Labour per firm decreases to maintain fixed scale given better technology. Therefore technological improvement causes firms to maintain a fixed capital stock, but reduce employment, and in aggregate the number of firms increases which expands aggregate output $Y_{A}^{*}=N_{A}^{*} y^{*}$, but average firm size does not change.

The steady state expression for output per firm (35) gives fixed costs as a proportion of variable cost $\frac{\phi}{y^{*}}=\frac{1-(1-\zeta) \nu}{\nu(1-\zeta)} \cdot{ }^{47}$ For a calibration of $\nu=0.8$ then our model implies overheads as a proportion of output in steady state vary from 0.25 with perfect competition $(\zeta=0)$ to 0.56 when the Lerner Index is $\zeta=0.2 .{ }^{48}$ With logarithmic utility in

\footnotetext{
${ }^{45} \eta=\frac{1}{F E}$ where $F E=\frac{d L}{d w} \frac{w}{L}$ is the Frisch elasticity which captures elasticity of hours worked to the wage rate, given a constant marginal utility of wealth. So it captures the substitution effect of a change in the wage rate on labour supply. $\eta=0$ is indivisible labour, assuming a higher Frisch elasticity of labour supply, i.e. $\eta \rightarrow 0$, strengthens results as hours respond more strongly.

${ }^{46}$ This is shown in Appendix D and can be observed directly from the steady-state conditions.

${ }^{47}$ Variable costs are equivalent to output in steady state since $y=d+r k+w l$, and $d^{*}=0$.

${ }^{48} \zeta=0.2$ implies a price-over-marginal-cost markup of $\mu=\frac{1}{1-\zeta}=\frac{\theta}{\theta-1}=1.2$ and intersector substitutability $\theta=6$. In general estimates of markups in value added data range from 1.2 to 1.4 , and in gross output they vary between 1.05 and 1.15, see Basu and Fernald 2001 and Morrison 1992
} 
consumption $(\sigma=1)$, then labour elasticity $\eta$ does not affect firms $N^{*}$, and in turn technology will not affect long-run labour. Table 1 summarizes the parameter values we use for simulation exercises. This calibration implies $C U=0.8$ with $\zeta=0.05$ and $C U=0.44$

$\begin{array}{ccccccccc}\zeta & \alpha & \beta & \phi & \gamma & A & \sigma & \rho & \eta \\ \{0.05,0.2\} & 0.3 & 0.5 & 0.3 & 50.0 & \{1.0,1.01\} & 1.0 & 0.025 & 0.0\end{array}$

Table 1: Parameter Values for Numerical Exercises

with $\zeta=0.2$. $\xi$ is chosen such that steady-state labour is normalized to one $\left(L^{*}=1\right)$. Dynamic barriers to entry $\gamma$ only affect model dynamics, not steady state outcomes, we choose this parameter to be large enough so that number of firms adjusts more slowly than capital. This implies that capital per firm increases following a positive shock before firm adjustment catches up to revert it to its long-run level which is unchanged.

\subsection{Dynamics}

The specific dynamical system and intratemporal condition for the parametric case specification are given in Appendix E. We solve the four dimensional system locally for trajectories of the variables over $t$. The system is nonlinear, so we linearize it to the form $\dot{X}=\mathbf{J}\left(X-X^{*}\right)$ where $X=[C, E, K, N]^{\prime}$. We then analyse the Jacobian matrix $\mathbf{J}: \mathbb{R}^{4} \rightarrow \mathbb{R}^{4}$ where each element is a respective derivative evaluated at steady state.

$$
\left[\begin{array}{c}
\dot{C} \\
\dot{E} \\
\dot{K} \\
\dot{N}
\end{array}\right]=\left.\left[\begin{array}{cccc}
\frac{C}{\sigma} r_{C} & 0 & \frac{C}{\sigma} r_{K} & \frac{C}{\sigma} r_{N} \\
-\frac{d_{C}}{\gamma} & \rho & -\frac{d_{K}}{\gamma} & -\frac{d_{N}}{\gamma} \\
Y_{C}-1 & 0 & Y_{K} & Y_{N} \\
0 & 1 & 0 & 0
\end{array}\right]\right|^{*}\left[\begin{array}{l}
C-C^{*} \\
E-E^{*} \\
K-K^{*} \\
N-N^{*}
\end{array}\right]
$$

Proposition 10. For the case of real roots, the economy is locally asymptotically unstable. A 2d-stable manifold exists in capital and number of firms.

Proof. Appendix E.

Proposition 10 formalizes quasi-fixity of capital and number of firms $N_{A}(0)=K_{A}(0)=$ 0 which we use to prove our main result (Theorem 1). With saddle dynamics variables 
on the system's stable manifold are predetermined. They do not respond on impact of a shock (Caputo 2005, p.426), instead jump variables $(C, E)$ move instantaneously to put the system on the stable manifold, and subsequently the state variables $(K, N)$ converge to the long-run steady state. ${ }^{49}$

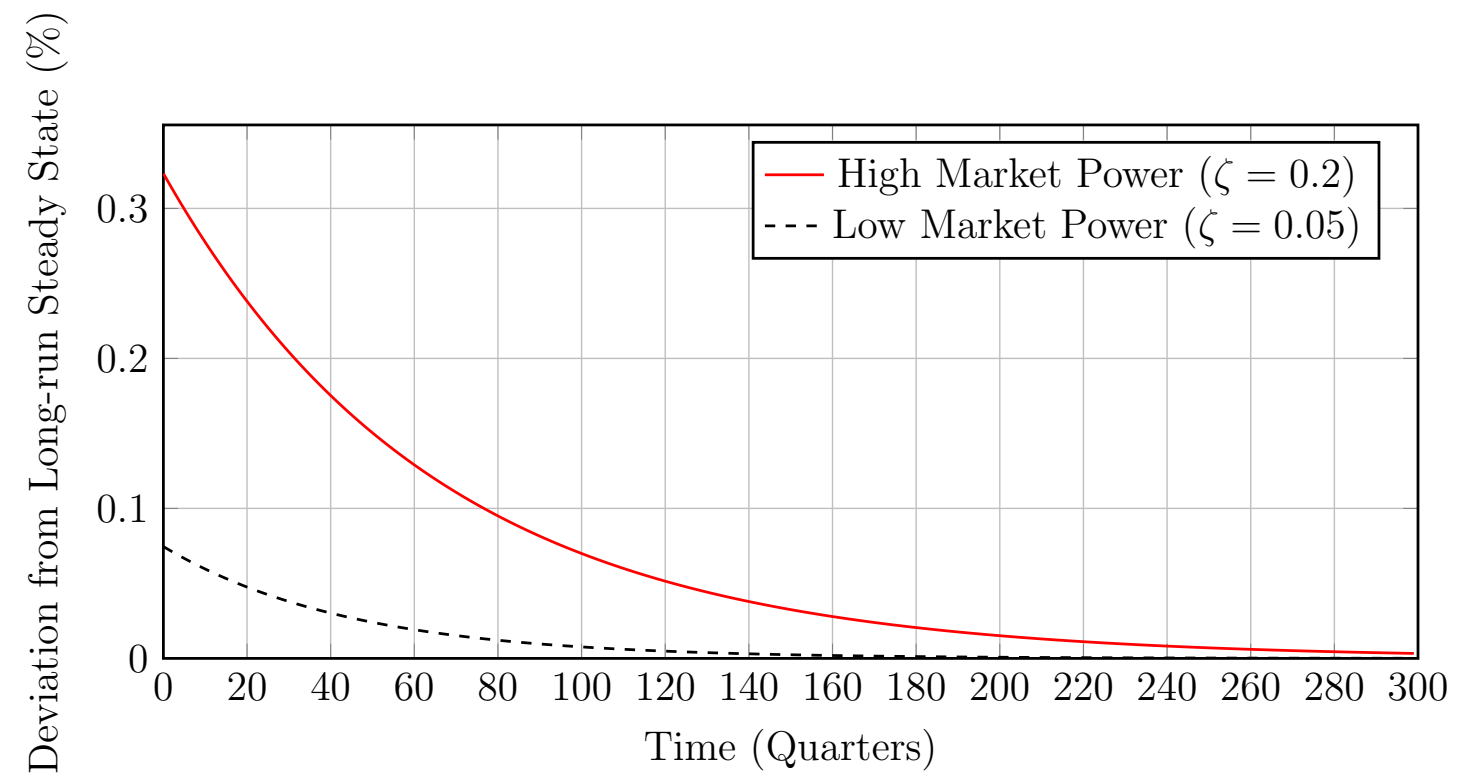

Figure 5: Measured Productivity Overshooting

Figure 5 illustrates Theorem 1 numerically. It shows that after a once-and-for-all $1 \%$ technology improvement $(A=1$ to $A=1.01)$ measured productivity overshoots its new long-run level by $0.32 \%$, and as market power decreases $\zeta=0.05$ the effect is weaker (Corollary 3). Figure 6 shows the transmission of the positive deterministic shock through the model's underlying variables. The simulations verify the steady-state algebra for the Cobb-Douglas production function. Namely that capital, consumption and number of firms increase proportionally in the long run - each increasing $2 \%$ for this numerical example - and therefore capital and consumption per firm are unaffected by a permanent technology shock in the long run. Furthermore, because we specify logarithmic consumption $\sigma=1$, income and substitution effects cancel-out such that long-run labour is unaffected by the technology increase. ${ }^{50}$

\footnotetext{
${ }^{49}$ The supplementary appendix defines the stable manifold. It shows that $K, N$ do not respond on impact $t=0$, whereas $C, E$ respond instantaneously. The simulations in figure 6 illustrate this.

${ }^{50}$ We plot the labour response separately for clarity - the response is an order of magnitude less than
} 


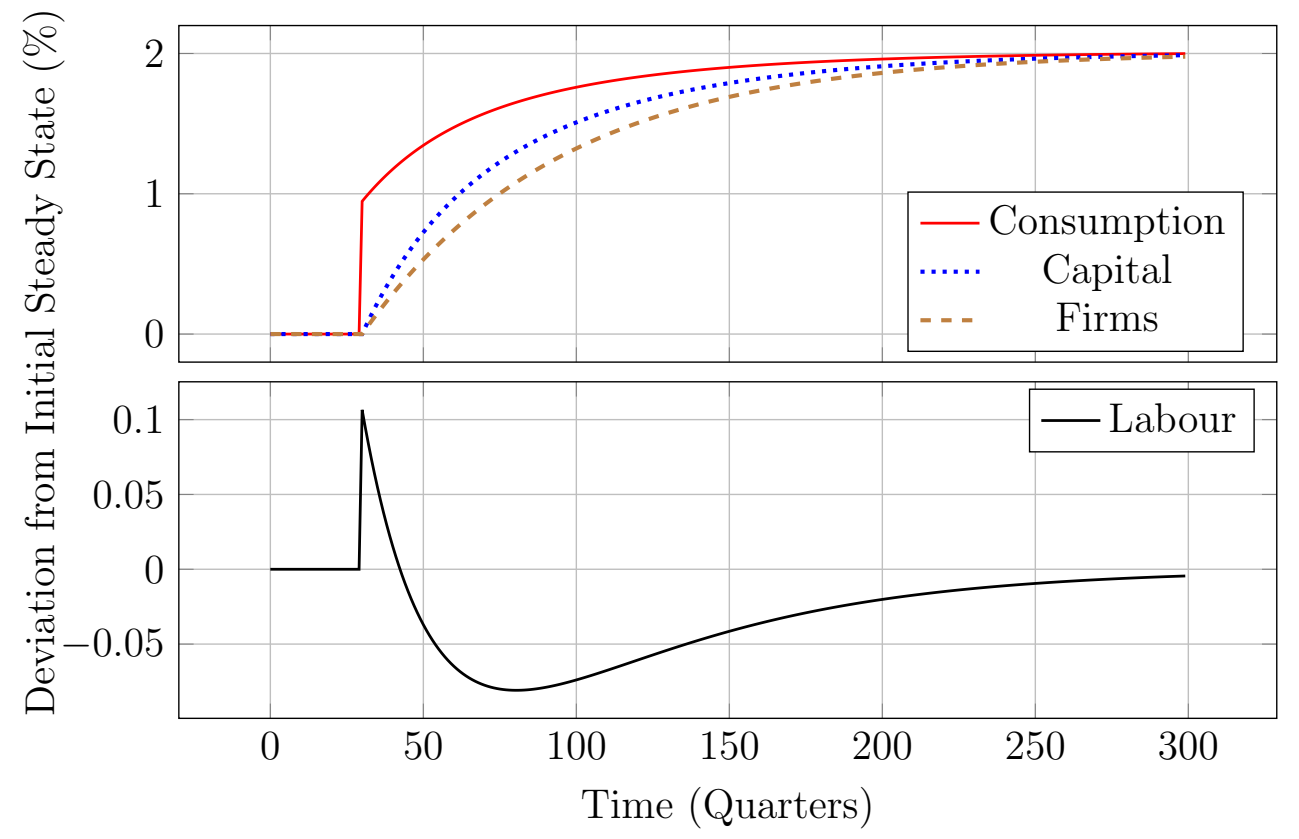

Figure 6: Permanent 1\% Technology Shock Impulse Responses

As explained by our theoretical discussion, the positive technology shock causes capital and number of firms to begin at their initial pre-shock steady state and start increasing over time as they converge to the new steady state with improved technology. It is this slow response of number of firms to the shock which leads to the productivity overshooting shown in figure 5 . And the slower the response $\gamma \rightarrow \infty$ of firms the more persistent the endogenous effect. ${ }^{51}$ We can also see that the number of firms increases at a decreasing rate, reflecting that entry is initially high to arbitrage large profits, but diminishes over time as congestion effects increase. In the long run, entry is zero as the number of firms is fixed at its new long-run level. Consumption jumps on impact, which implies labour jumps too. The short-run rise in labour can be understood through the static labour condition

$$
L(C, K, N)=\left(\frac{(1-\zeta) A K^{\alpha} \beta N^{1-(\alpha+\beta)}}{\xi C^{\sigma}}\right)^{\frac{1}{1+\eta-\beta}}
$$

Given $K, N$ are initially fixed at their old steady state level, the increase in $A$ on impact the other variables.

${ }^{51}$ This can be fomalized by showing the regulatory parameter (dynamic barrier to entry) $\gamma$ strictly decreases the system's eigenvalues, and hence more entry regulation slows recovery after a shock as it inhibits firm dynamics. See Aloi, Dixon, and Savagar 2019. 
offsets the increase in $C$ on impact creating an increase in $L$. Subsequently, as $K, N$ are able to adjust their increase is weaker than the increase in $C$ and hence $L$ decreases. After some point, the increasing $C$ becomes weaker than the increasing $K, N$ which leads to the hump-shape, and eventual increase in $L$ back to its steady state. ${ }^{52}$

\subsection{Capital Utilization and Capacity Utilization}

We have shown that slow firm entry causes variations in capacity utilization which creates endogenous productivity fluctuations. However RBC literature emphasizes that 'capital utilization' can account for endogenous variations in measured TFP, which amplify exogenous technology shocks. ${ }^{53}$ In this section we include capital utilization in conjunction with our capacity utilization mechanism, and find they are of equal importance.

In the absence of endogenous labour, RBC literature uses the terms capacity utilization and capital utilization interchangeably. ${ }^{54}$ We define capacity utilization as production relative to a full capacity benchmark (Definition 3). Whereas, capital utilization is the endogenous depreciation of capital based on its usage. Capital utilization nests a new functional in the firm production function. ${ }^{55}$ The utilization function $\mathfrak{u}(t): K \times N \rightarrow$ $(0,1)$ reflects the intensity of capital usage, so the capital utilization production function is

$$
y=A F(\mathfrak{u} k, l)-\phi
$$

In addition to the modified production function, capital utilization will affect depreciation in the budget constraint. This creates a difference between the household's market return from lending capital $r(t)$ and the firm's cost of renting capital $R(t)$, which are equivalent in the no depreciation case. The relationship is that the return to lending capital is the

\footnotetext{
${ }^{52}$ In Appendix $G$ we show quantitatively that our model results are robust to different entry cost specifications. We show that the endogenous productivity effects we present exist in the Bilbiie, Ghironi, and Melitz 2012 framework where the entry cost is output denominated. Furthermore, we show that these endogenous productivity effects disappear as we move to perfect competition.

${ }^{53}$ For example, Kydland and Prescott 1988, Shapiro 1993, Bils and Cho 1994, Burnside, Eichenbaum, and Rebelo 1995, King and Rebelo 1999

${ }^{54}$ For example, Greenwood, Hercowitz, and Huffman 1988, and Benhabib, Nishimura, and Shigoka 2008.

${ }^{55}$ King and Rebelo 1999 were early adopters of the preciser term capital utilization, and Basu and Fernald 2001 also emphasize the distinction.
} 
rental paid by firms less depreciation $r(t)=R(t)-\delta(\mathfrak{u}, t)$.

We assume that the rate of capital depreciation $\delta(\mathfrak{u}, t) \in(0,1)$ is an increasing convex function of the rate of utilization $\mathfrak{u} \in(0,1)$ given by

$$
\delta=z \mathfrak{u}^{\vartheta}
$$

where $\vartheta>1$ and $z \in R_{+} \cdot{ }^{56}$ Therefore $z=0$ and $\mathfrak{u}=1$ cause production (51) and depreciation (52) to collapse to the no utilization setup. Since utilization is endogenous it cannot be exogenously set to full utilization $\mathfrak{u} \rightarrow 1$, but the exogenous convexity parameter can be made large to achieve this effect $\lim _{\vartheta \rightarrow \infty} \mathfrak{u}=1$. The intuition is that $\vartheta$ is the elasticity of $\delta_{\mathfrak{u}} \cdot{ }^{57}$ When it is large the marginal cost of utilization (replacement rate) $\delta_{\mathfrak{u}}$ responds elastically to utilization which encourages full utilization. It is calibrated to 1.1 in King and Rebelo 1999, 1.4 in Wen 1998, and between 1.25 and 2.0 in Benhabib, Nishimura, and Shigoka 2008. We use $\vartheta=1.4, z=1.0$ and the table 1 numerical values.

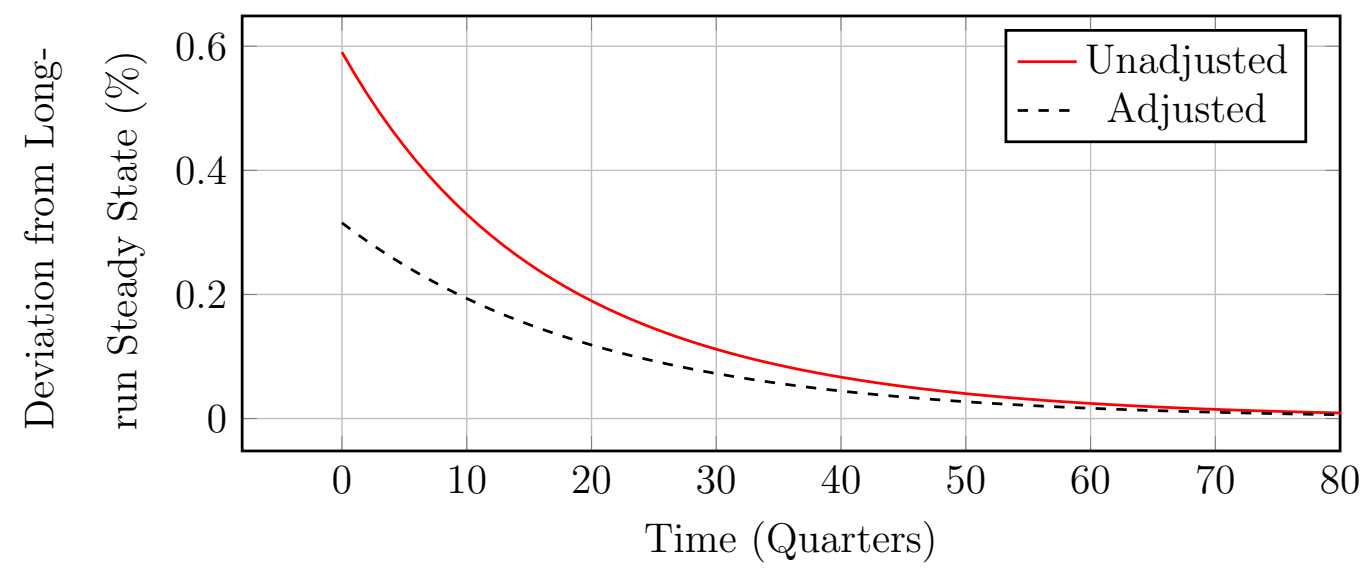

Figure 7: Capital Utilization Adjusted and Unadjusted Measured Productivity

Figure (5.3) shows that overshooting is $0.6 \%$ which comprises $0.31 \%$ from capacity utilization and $0.29 \%$ from capital utilization. Clearly the adjusted overshooting is the same as figure 5 with no capital utilization. This shows that King and Rebelo 1999 suggested 'modified Solow Residual' works well at eradicating the capital utilization bias, leaving only the capacity utilization bias. The unadjusted measure fails to account for

\footnotetext{
${ }^{56}$ This parametric restriction imposes a convex cost structure on capital utilization so there is an interior solution for $\mathfrak{u}$ in steady state. If $\vartheta \leq 1$ then the optimal rate of capital utilization is always $\mathfrak{u}=1$ i.e. full utilization.

${ }^{57} \mathfrak{u} \frac{\delta_{\mathfrak{u u}}}{\delta_{\mathfrak{u}}}=\vartheta-1$, King and Rebelo 1999 use notation $\vartheta-1=\xi$ and calibrate to 0.1 .
} 
$\mathfrak{u}$ in the denominator of the measured productivity definition TFP unadj. $=y / F(k, l)^{\frac{1}{\nu}}$ whereas the adjusted measure ensures the denominator is correctly specified TFP ${ }^{\text {adj. }}=$ $y / F(\mathfrak{u} k, l)^{\frac{1}{\nu}}$, where for both definitions $y$ includes utilization as in (51).

\section{Empirical Implications}

As figure 5 demonstrates, a testable implication of our theory is that TFP varies more in markets that are less competitive. Using CompNet data (Lopez-Garcia and Di Mauro 2015) from the ECB we show that this relationship holds across most European countries. Figure 6 shows that, in each country, 2-digit sectors with more variable measured TFP tend to be those with higher price-cost margins. ${ }^{58}$ The positive relationship holds at the 90th percentile confidence interval for seven countries and is statistically insignificant for the remaining three (Portugal, Romania, Estonia). There are typically 58 scatter points underlying each linear regression plot. An individual point is an aggregation of firm-level observations into the 2-digit sector. This is the lowest level of aggregation provided by CompNet and is reported annually (max. 2000-2012). On the y-axis, a point represents the variance across years for median TFP in a 2-digit sector. On the $\mathrm{x}$-axis, a point is the mean across years of the turnover-weighted PCM in a 2-digit sector.

\footnotetext{
${ }^{58}$ We use CompNet data because it provides off-the-shelf measures of price-cost margins (i.e. markups) and TFP. Both of which are contentious measures to construct. Appendix H provides data and cleaning details.
} 

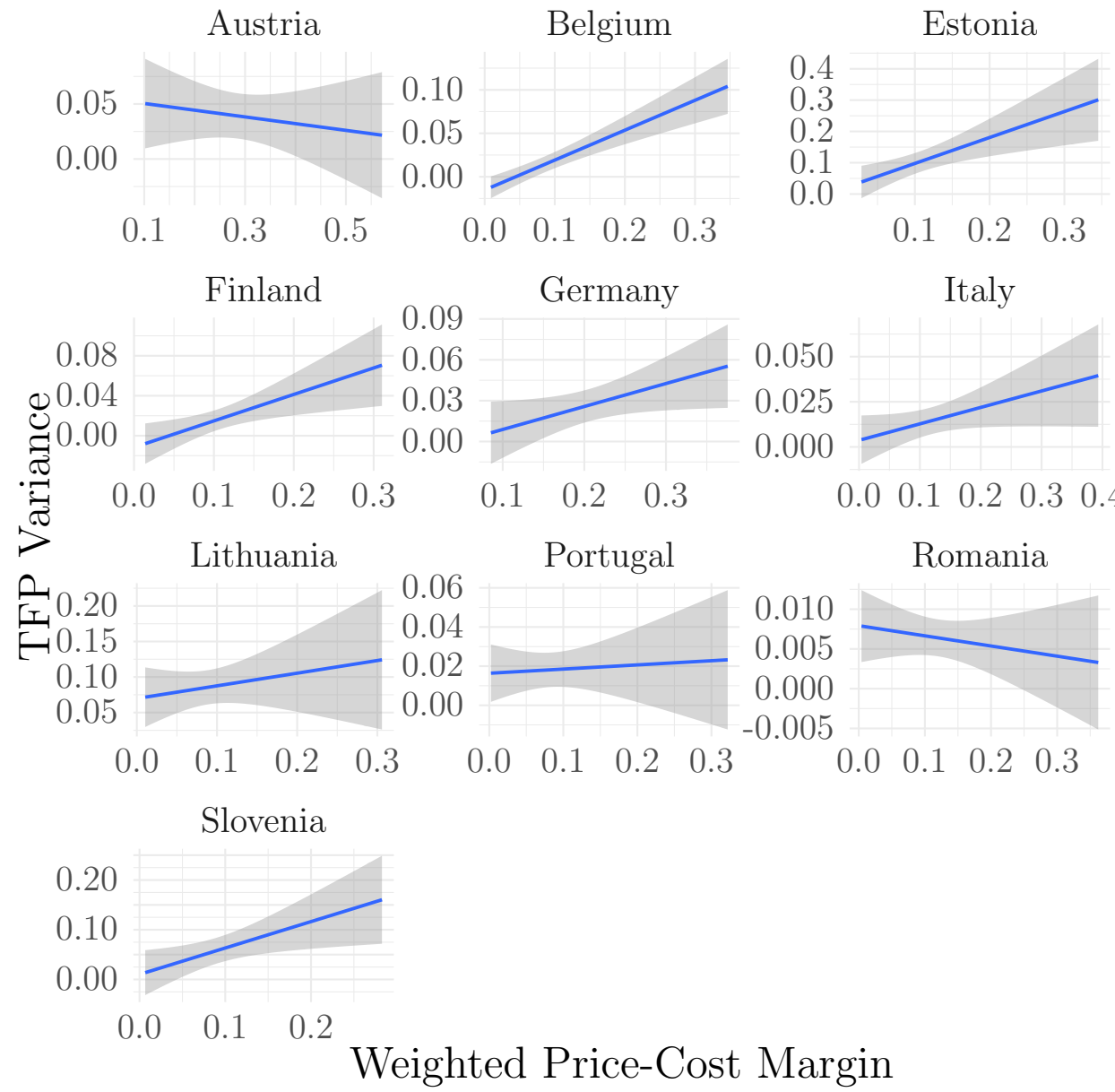

Figure 8: TFP Variance and Competition Across Countries

\section{Summary}

This paper shows that with imperfect competition, non-instantaneous firm entry causes endogenous productivity dynamics because incumbent firms vary their excess capacity in the short-run absence of entry. Crucially it is the short-run absence of entry that creates procyclical productivity, and subsequent entry decreases productivity through business stealing. This is distinct from firm-dynamics, aggregate-productivity literature that focuses on the long-run pro-competitive effect of entry on markups or heterogeneous firm composition. This literature analyzes free-entry outcomes rather than intertemporal effects as entry slowly adjusts to arbitrage profits. Our methodological contribution is to offer a tractable theory of endogenous firm entry over the business cycle with imperfect 
competition and endogenous sunk costs. Our static analysis shows that imperfect competition causes excess capacity and locally increasing returns. Our dynamic analysis shows that this excess capacity varies countercyclically in the short-run in response to shocks, but returns in the long-run when entry has adjusted. Quantitatively we show that the endogenous productivity movements that slow firm entry creates are as important as the popular capital utilization mechanism of traditional RBC papers. 
A supplementary appendix expands the results and details of this appendix.

\section{A Decentralised Model Equations}

Collecting the model equilibrium conditions recursively gives

$$
\begin{aligned}
& k=\frac{K}{N} \\
& l=\frac{L}{N} \\
& y=A F(k, l)-\phi \\
& Y=N y \\
& d=y(1-(1-\zeta) \nu)-\nu(1-\zeta) \phi \\
& r=(1-\zeta) A F_{k}(k, l) \\
& w=(1-\zeta) A F_{l}(k, l) \\
& w=-\frac{u_{L}(L)}{u_{C}(C)} \\
& \dot{C}=\frac{C}{\sigma(C)}(r-\rho), \quad \sigma(C)=-\frac{C u_{C C}}{u_{C}} \\
& \dot{E}=r E-\frac{d}{\gamma}, \quad \gamma>0 \\
& \dot{K}=Y-\frac{\gamma}{2} E^{2}-C \\
& \dot{N}=E \\
& K(0)=K_{0} \\
& N(0)=N_{0} \\
& \lim _{t \rightarrow \infty} K(t) u_{C}(t) e^{-\rho t}=0 \\
& \lim _{t \rightarrow \infty} N(t) q(t) u_{C}(t) e^{-\rho t}=0
\end{aligned}
$$

\section{A.1 Reduced-form Market Equilibrium}

Substituting out $k, l, y, Y, d, r$ from the four differential equations and remembering that labour is in terms of underlying states $L(C, K, N)$ (through combining the intratemporal condition (4) and labour demand condition (14)), we attain the reduced-form equilibrium 
conditions as a four dimensional dynamical system $(C, E, K, N)$ with the four boundary conditions (two initial condition and two transversality conditions) $)^{59}$

$$
\begin{aligned}
\dot{K} & =N^{1-\nu} A F(K, L)-N \phi-\frac{\gamma}{2} E^{2}-C \\
\dot{N} & =E \\
\dot{C} & =-\frac{u_{C}}{u_{C C}}\left((1-\zeta) A N^{1-\nu} F_{K}-\rho\right) \\
\dot{E} & =\left((1-\zeta) A N^{1-\nu} F_{K}\right) E-\frac{A N^{-\nu} F(K, L)(1-(1-\zeta) \nu)-\phi}{\gamma}
\end{aligned}
$$

\section{A.2 Decentralised Steady State}

In steady state capital, number of firms and consumption are stationary $\dot{K}=\dot{N}=\dot{C}=$ $\dot{E}=0$ at $\left(C^{*}, K^{*}, N^{*}, E^{*}\right)$. Labour is a function of the system variables $L^{*}\left(C^{*}, K^{*}, N^{*}\right)$ through the static intratemporal condition (32), repeated here for steady state

$$
(1-\zeta) A F_{l}\left(\frac{K^{*}}{N^{*}}, \frac{L^{*}}{N^{*}}\right)=-\frac{u_{L}\left(L^{*}\right)}{u_{C}\left(C^{*}\right)}
$$

Therefore in steady state the following system determines $\left(C^{*}, K^{*}, N^{*}, E^{*}\right)$.

$$
\begin{array}{rlrl}
\dot{C} & =0: & (1-\zeta) A F_{k}\left(\frac{K^{*}}{N^{*}}, \frac{L^{*}}{N^{*}}\right) & =\rho \\
\dot{E}=0: & F\left(\frac{K^{*}}{N^{*}}, \frac{L^{*}}{N^{*}}\right) & =\frac{\phi}{A(1-(1-\zeta) \nu)} \\
\dot{K}=0: & N^{*}\left[A F\left(\frac{K^{*}}{N^{*}}, \frac{L^{*}}{N^{*}}\right)-\phi\right] & =C^{*} \\
\dot{N} & =0: & E^{*} & =0
\end{array}
$$

The entry arbitrage condition (59) implies profits are zero, which determines steady-state variable production and therefore firm output $y^{*}$. Given $y^{*}$, the aggregate resource constraint (60) determines steady-state consumption in terms of $N^{*}$ since $C^{*}=N^{*} y^{*}$, which gives labour $L^{*}\left(C^{*}\left(N^{*}\right), K^{*}, N^{*}\right)$ in $K^{*}, N^{*}$ terms through the intratemporal condition (57). Thus (58) and (59) are in $K^{*}, N^{*}$ terms and can be solved simultaneously.

\footnotetext{
${ }^{59}$ We use Euler's homogeneous function theorem where $k=K / N$ and $l=L / N$ then $F_{k}(k, l)=$ $N^{1-\nu} F(K, L)$ and $F(k, l)=N^{-\nu} F(K, L)$
} 


\section{B Planner Problem}

A planner maximizes aggregate utility choosing control variables consumption, labour and entry subject to state variables capital and number of firms:

$$
\max _{[C(t), L(t), E(t)]_{t=0}^{\infty}} U:=\int_{0}^{\infty} u(C, L) e^{-\rho t} \mathrm{dt}
$$

subject to

$$
\begin{aligned}
\dot{K} & =N^{1-\nu} A F(K, L)-N \phi-Z(E)-C \\
\dot{N} & =E \\
K(0) & =K_{0} \\
N(0) & =N_{0} \\
\lim _{t \rightarrow \infty} K(t) u_{C}(t) e^{-\rho t} & =0 \\
\lim _{t \rightarrow \infty} N(t) E(t) u_{C}(t) e^{-\rho t} & =0
\end{aligned}
$$

To solve this optimization problem, form the current-value Hamiltonian

$$
\begin{aligned}
\hat{\mathcal{H}}\left(K, C, v_{1}, N, E, v_{2}, L\right)=u & (C, L) \\
& +v_{1}\left(N^{1-\nu} A F(K, L)-N \phi-Z(E)-C\right) \\
& +v_{2} E
\end{aligned}
$$


The two co-state variables have the following interpretations: $v_{1}$ is the shadow price of capital and $v_{2}$ is the shadow price of a firm. The optimization conditions are:

$$
\begin{array}{cr}
\hat{\mathcal{H}}_{C}=0: & u_{C}(C)-v_{1}=0 \\
\hat{\mathcal{H}}_{L}=0: & u_{L}(L)+v_{1} N^{1-\nu} A F_{L}(K, L)=0 \\
\hat{\mathcal{H}}_{E}=0: & -v_{1} Z^{\prime}(E)+v_{2}=0 \\
\hat{\mathcal{H}}_{K}=\rho v_{1}-\dot{v}_{1}: & v_{1}\left(N^{1-\nu} A F_{K}(K, L)\right)=\rho v_{1}-\dot{v}_{1} \\
\hat{\mathcal{H}}_{N}=\rho v_{2}-\dot{v}_{2}: & v_{1}\left[(1-\nu) N^{-\nu} A F(K, L)-\phi\right]=\rho v_{2}-\dot{v}_{2} \\
\hat{\mathcal{H}}_{v_{1}}=\dot{K}: & \dot{K}=N^{1-\nu} A F(K, L)-N \phi-Z(E)-C \\
\hat{\mathcal{H}}_{v_{2}}=\dot{N}: &
\end{array}
$$

From (70) and (71), we have a standard intratemporal condition

$$
-\frac{u_{L}}{u_{C}}=N^{1-\nu} A F_{L}(K, L)
$$

From (70) if we take the time derivative

$$
\dot{v}_{1}=u_{C C} \dot{C}
$$

Therefore from $(73)$

$$
\dot{C}=-\frac{u_{C}}{u_{C C}}\left(N^{1-\nu} A F_{K}(K, L)-\rho\right)
$$

From (72) we get that the market price of a firm in terms of the shadow value of wealth (an extra unit of capital) equates to the marginal cost of firm entry and noting $Z=\gamma \frac{E^{2}}{2}$ we have

$$
q \equiv \frac{v_{2}}{v_{1}}=Z^{\prime}(E)=\gamma E
$$

From (74)

$$
\left[(1-\nu) N^{-\nu} A F(K, L)-\phi\right]=\rho q-\frac{\dot{v}_{2}}{v_{1}}
$$


And from (73)

$$
\frac{\dot{v}_{2}}{v_{1}}=\dot{q}+q\left[\rho-N^{1-\nu} A F_{K}(K, L)\right]
$$

Then

$$
\dot{q}=q N^{1-\nu} A F_{K}(K, L)-\left[(1-\nu) N^{-\nu} A F(K, L)-\phi\right]
$$

A familiar way to write this relationship is in a standard arbitrage equation form (stationary Hamilton-Jacobi-Bellman equation)

$$
r q=d+\dot{q}
$$

The opportunity cost $r$ of investing in a firm at price $q$ equates to the dividends (operating profits) $d$ from owning a firm plus the change in its underlying value $\dot{q}$. The opportunity cost of investing in a firm is forgone $r$ that you would get from the alternative of renting capital. Hence, comparing (83) with (84), the opportunity cost of firm investment is

$$
r=N^{1-\nu} A F_{K}(K, L)
$$

and operating profits ( $a k a$ dividends) are

$$
d=(1-\nu) N^{-\nu} A F(K, L)-\phi
$$

Bringing together these optimality conditions gives the standard planner equilibrium.

\section{B.1 Reduced-form Planner Allocation}

We can present this in a reduced-form fashion as a four-dimensional dynamical system in terms of $\{C, E, K, N\}$ with four boundary conditions (two initial condition and two transversality conditions). Labour is implicitly defined as a function of the other model variables, $L(C, K, N)$, through the intratemporal condition.

$$
L(C, K, N): \quad-\frac{u_{L}(L)}{u_{C}(C)}=N^{1-\nu} A F_{L}(K, L)
$$


Given $Z(E)=\frac{\gamma E^{2}}{2}$ in the aggregate resource constraint, and writing (83) in terms of $E$ using $\dot{q}=Z^{\prime \prime}(E) \dot{E}=\gamma \dot{E}$ to get (85), we can summarize the planner optimality conditions as

$$
\begin{aligned}
& \dot{C}=-\frac{u_{C}}{u_{C C}}\left(N^{1-\nu} A F_{K}(K, L)-\rho\right) \\
& \dot{E}=N^{1-\nu} A F_{K}(K, L) E-\frac{(1-\nu) N^{-\nu} A F(K, L)-\phi}{\gamma} \\
& \dot{K}=N^{1-\nu} A F(K, L)-N \phi-\frac{\gamma E^{2}}{2}-C \\
& \dot{N}=E
\end{aligned}
$$

Additionally there are four boundary conditions (65), (66), (67), (68): two initial conditions on the state variables and two transversality conditions.

\section{B.2 Equivalence of Planner Outcome and Market Outcome}

Proof of Proposition 3. Evaluating the decentralised equilibrium conditions (53), (54), (55), (56) at perfect competition $\zeta=0$ results in equivalent equilibrium conditions to the planner solution (79), (85), (63), (64).

\section{Labour Market}

The supplementary appendix gives an extensive discussion of the labour market. Treating labour as an implicit function, take the derivative with respect to $C, K, N$ of the general intratemporal condition at factor market equilibrium as in (32)

$$
u_{L}(L)+u_{C}(C) w(C, K, N)=0
$$


then substitute in the total derivatives of wage, which are

$$
\begin{aligned}
w(C, K, N) & =(1-\zeta) A N^{1-\nu} F_{L}(K, L) \\
w_{L} & =(1-\zeta) A N^{1-\nu} F_{L L}(K, L)<0 \\
w_{C} & =w_{L} L_{C} \\
w_{K} & =\frac{\partial w}{\partial K}+w_{L} L_{K} \\
w_{N} & =\frac{\partial w}{\partial N}+w_{L} L_{N}
\end{aligned}
$$

and collect terms in labour response of the left-hand side.

$$
\begin{aligned}
L_{C} & =\frac{-u_{C C} w}{u_{L L}+u_{C} w_{L}}=\frac{u_{L}}{u_{L L}+u_{C} w_{L}} \frac{u_{C C}}{u_{C}}<0 \\
L_{K} & =\frac{-u_{C}}{u_{L L}+u_{C} w_{L}} \frac{\partial w}{\partial K}=\frac{u_{L}}{u_{L L}+u_{C} w_{L}} \frac{F_{L K}}{F_{L}}>0 \\
L_{N} & =\frac{-u_{C}}{u_{L L}+u_{C} w_{L}} \frac{\partial w}{\partial N}=\frac{u_{L}}{u_{L L}+u_{C} w_{L}} \frac{1-\nu}{N}>0, \quad \nu \in(0,1)
\end{aligned}
$$

The consistent denominator is $\hat{\mathcal{H}}_{L L}=u_{L L}+u_{C} w_{L}$, which is the intratemporal condition differentiated with respect to $L$. It is negative which reflects that utility is decreasing in labour.

Proof of Proposition 4. Follows from (94) as $\nu \in(0,1)$.

The remark that $\left.L_{N}\right|^{\nu=1}=0$ follows trivially, remembering imperfect competition must hold for constant returns existence when there is an overhead cost.

\section{Additional Proofs}

Proof of Proposition 1. Total operating profits are aggregate output less total variable $\operatorname{costs}^{60}$

$$
\begin{aligned}
N d & =N y-N(r k+w l) \\
& =Y-N^{1-\nu}(1-\zeta) \nu A F(K, L)
\end{aligned}
$$

\footnotetext{
${ }^{60}$ The fixed cost $\phi$ denominated in terms of output. It could be denomiated in terms of wages so it would appear in the variable costs component not $y$.
} 
substitute out $N=\frac{Y}{y}$ and collect $Y$

$$
\begin{aligned}
Y & =\left(1-\frac{d}{y}\right)^{-\frac{1}{\nu}}\left(\left(\frac{1}{y}\right)^{1-\nu} A F(K, L)(1-\zeta) \nu\right)^{\frac{1}{\nu}} \\
& =y\left(\frac{(1-\zeta) \nu A}{y-d}\right)^{\frac{1}{\nu}} F(K, L)^{\frac{1}{\nu}}
\end{aligned}
$$

use $y=\frac{(1-\zeta) \nu \phi+d}{1-(1-\zeta) \nu}$ (which comes from $d=y-(1-\zeta) \nu A F(k, l)$, substitute out $y=$ $A F(k, l)-\phi$ then rearrange for $\left.F(k, l)=\frac{d+\phi}{A(1-(1-\zeta) \nu)}\right)$ thus

$$
\frac{Y}{F(K, L)^{\frac{1}{\nu}}}=\left(\frac{A}{d+\phi}\right)^{\frac{1}{\nu}}(1-(1-\zeta) \nu)^{\frac{1}{\nu}-1}[(1-\zeta) \nu \phi+d]
$$

Proof of Proposition 5. In each case take the total derivative of $y$ and then substitute in the labour effect from $\mathrm{C}$.

$$
\begin{aligned}
y & =A N^{-\nu} F(K, L)-\phi \\
y_{C} & =A n^{-\nu} F_{L} L_{C}=A N^{-\nu} F_{L} \frac{u_{L}}{u_{L L}+u_{C} w_{L}} \frac{u_{C C}}{u_{C}}=-A N^{-\nu} F_{L} \frac{u_{C C} w}{u_{L L}+u_{C} w_{L}}<0 \\
y_{K} & =A N^{-\nu}\left(F_{K}+F_{L} L_{K}\right)=A N^{-\nu}\left(F_{K}+\frac{u_{L}}{u_{L L}+u_{C} w_{L}} F_{L K}\right)>0
\end{aligned}
$$

An entrant's effect on the intensive margin $y_{N}$ is more complex because labour opposes the business stealing effect. First substitute in the labour response $L_{N}$

$$
\begin{aligned}
y_{N} & =-\nu A N^{-\nu-1} F(K, L)+A N^{-\nu} F_{L} L_{N} \\
& =A N^{-\nu-1}\left[-\nu F(K, L)+\frac{u_{L}}{u_{L L}+u_{C} w_{L}}(1-\nu) F_{L}\right]
\end{aligned}
$$

Then, by Euler's homogeneous function theorem, use that $\nu F=F_{K} K+F_{L} L$ and $(\nu-$ 1) $F_{L}=F_{L L} L+F_{L K} K$ and using the relationship $u_{C} w_{L}=u_{C} w \frac{F_{L L}}{F_{L}}=-u_{L} \frac{F_{L L}}{F_{L}}$ since $u_{C} w=-u_{L}$. Hence

$$
y_{N}=A N^{-\nu-1} \frac{u_{L}}{u_{L L}+u_{C} w_{L}}\left[-\nu F(K, L) \frac{u_{L L}}{u_{L}}+K\left(\frac{F_{L L}}{F_{L}} F_{K}-F_{L K}\right)\right]<0
$$

Proof of Corollary 1. The relationship between TFP and output is convex reflecting the 
U-shaped cost curve. Rearrange TFP $=\frac{y}{F(k, l)^{\frac{1}{\nu}}}=\frac{A^{\frac{1}{\nu}} y}{(y+\phi)^{\frac{1}{\nu}}}$, then take the derivative with respect to $y$ :

$$
\operatorname{TFP}_{y}=\left(\frac{A}{y+\phi}\right)^{\frac{1}{\nu}}\left[1-\frac{y}{\nu(y+\phi)}\right]
$$

Equating to zero and rearranging for output gives (37), then substitution gives (38).

Proof of Corollary 2. Use Cramer's rule to determine the effect of a change in technology on $k^{*}, l^{*}$. From (58) and (59), technology decreases per firm marginal product of capital, and variable production

$$
\begin{aligned}
\left.F_{k}\right|_{A} ^{*} & =\frac{-1}{A^{2}} \frac{\rho}{(1-\zeta)}<0 \\
F_{A}^{*} & =\frac{-1}{A^{2}} \frac{\phi}{(1-(1-\zeta) \nu)}<0
\end{aligned}
$$

In general

$$
\begin{aligned}
& F_{k k} k_{A}+F_{k l} l_{A}=F_{k A} \\
& F_{k} k_{A}+F_{l} l_{A}=F_{A} \\
& \underbrace{\left[\begin{array}{cc}
F_{k k} & F_{k l} \\
F_{k} & F_{l}
\end{array}\right]}_{\mathbf{H}}\left[\begin{array}{l}
k_{A} \\
l_{A}
\end{array}\right]=\left[\begin{array}{l}
F_{k A} \\
F_{A}
\end{array}\right] \\
& {\left[\begin{array}{l}
k_{A} \\
l_{A}
\end{array}\right]=\frac{1}{\operatorname{det}(\mathbf{H})}\left[\begin{array}{cc}
F_{l} & -F_{k l} \\
-F_{k} & F_{k k}
\end{array}\right]\left[\begin{array}{c}
F_{k A} \\
F_{A}
\end{array}\right]}
\end{aligned}
$$

Since $\operatorname{det}(\mathbf{H})=F_{k k} F_{l}-F_{k l} F_{k}<0$ and at steady state the effect of a change in technology on marginal product of capital and production is negative $\left(\left.F_{k}\right|_{A} ^{*}, F_{A}^{*}<0\right)$ then

$$
\begin{aligned}
& l_{A}^{*}=\frac{1}{\operatorname{det}(\mathbf{H})}\left(-\left.F_{k} F_{k}\right|_{A} ^{*}+F_{k k} F_{A}^{*}\right)<0 \\
& k_{A}^{*}=\frac{1}{\operatorname{det}(\mathbf{H})}\left(\left.F_{l} F_{k}\right|_{A} ^{*}-F_{k l} F_{A}^{*}\right) \gtreqless 0 \Longleftrightarrow \frac{F_{l}}{F_{k l}} \gtreqless \frac{(1-\zeta) \phi}{\rho(1-(1-\zeta) \nu)}
\end{aligned}
$$

Proof of Cobb-Douglas Capital Per Firm Inertia. In the parametric case of Cobb-Douglas production discussed below, remembering production function Hessian symmetry $F_{l k}=$ 
$F_{k l}$, we have $\frac{F_{l}^{*}}{F_{k l}^{*}}=\frac{\frac{\beta\left(y^{*}+\phi\right)}{A l l^{*}}}{\frac{\alpha\left(y^{*}+\phi\right)}{A k^{*}}}=\frac{\beta}{\alpha} \frac{k^{*}}{l^{*}}=\frac{\beta}{\alpha} \frac{K^{*}}{L^{*}}=\frac{(1-\zeta) \phi}{\rho(1-(1-\zeta) \nu)}$ which implies (108) holds with equality such that $k_{A}^{*}=0$. This is directly observable from the parametric steady-state outcomes (116).

\section{E Parameterized Model}

Under the functional forms we have assumed the intratemporal condition is

$$
L(C, K, N)=\left(\frac{(1-\zeta) A K^{\alpha} \beta N^{1-(\alpha+\beta)}}{\xi C^{\sigma}}\right)^{\frac{1}{1+\eta-\beta}}
$$

Hence substituting out $L(C, K, N)$ gives a 4 d dynamical system in $(C, E, K, N)$

$$
\begin{aligned}
\dot{C}= & \frac{C}{\sigma}\left[(1-\zeta) A \alpha K^{\alpha-1} L^{\beta} N^{1-(\alpha+\beta)}-\rho\right] \\
\dot{E}= & (1-\zeta) A \alpha K^{\alpha-1} L^{\beta} N^{1-(\alpha+\beta)} E \\
& \quad-\frac{1}{\gamma}\left(A K^{\alpha} L^{\beta} N^{-(\alpha+\beta)}(1-(1-\zeta) \nu)-\phi\right) \\
\dot{K}= & n\left[A K^{\alpha} L^{\beta} N^{-(\alpha+\beta)}-\phi\right]-\frac{\gamma}{2} E^{2}-C \\
\dot{N}= & E
\end{aligned}
$$

\section{E.1 Steady State}

Solving for steady state gives

$$
\begin{aligned}
N^{*}= & {\left[\frac { \beta } { \xi \nu ^ { \sigma } } \left\{\left(A\left(\frac{\alpha}{\rho}\right)^{\alpha}\right)^{1+\eta}(1-\zeta)^{\alpha(1+\eta)+\beta(1-\sigma)}\right.\right.} \\
& \left.\left.\left(\frac{1-(1-\zeta) \nu}{\phi}\right)^{1-\nu+\eta(1-\alpha)+\sigma \beta}\right\}^{\frac{1}{\beta}}\right]^{\frac{1}{\eta+\sigma}} \\
L^{*} & =N^{*}\left[\frac{1}{A}\left(\frac{\rho}{\alpha(1-\zeta)}\right)^{\alpha}\left(\frac{\phi}{1-(1-\zeta) \nu}\right)^{1-\alpha}\right]^{\frac{1}{\beta}} \\
K^{*} & =N^{*} \frac{\phi \alpha(1-\zeta)}{(1-(1-\zeta) \nu) \rho} \\
C^{*} & =N^{*} \frac{\phi(1-\zeta) \nu}{1-(1-\zeta) \nu} \\
E^{*} & =0
\end{aligned}
$$


The steady-state is defined in terms of parameters $\Omega=\{\alpha, \beta, \phi, \gamma, \xi, \rho, \eta, \zeta, \sigma\}$, where all except dynamic barriers to entry $\gamma$ enter the steady state. The number of firms is decreasing in fixed costs $\phi$, discount factor $\rho$, labour weight in utility $\xi$.

\section{E.2 Dynamics}

The Jacobian matrix of the parametric system (110), (111), (112), (113) evaluated at steady state is

$$
\begin{aligned}
& \mathbf{J}=\left.\left[\begin{array}{cccc}
\dot{C}_{C} & \dot{C}_{e} & \dot{C}_{K} & \dot{C}_{N} \\
\dot{E}_{C} & \dot{E}_{e} & \dot{E}_{K} & \dot{E}_{N} \\
\dot{K}_{C} & \dot{K}_{e} & \dot{K}_{K} & \dot{K}_{N} \\
\dot{N}_{C} & \dot{N}_{e} & \dot{N}_{K} & \dot{N}_{N}
\end{array}\right]\right|^{*} \\
& =\left[\begin{array}{cccc}
-\frac{\rho \beta}{1+\eta-\beta} & 0 & \frac{-\rho^{2} \nu(1-\nu+\eta(1-\alpha))}{(1+\eta-\beta) \sigma \alpha} & \frac{\phi(1-\zeta) \nu \rho(1-\nu)(1+\eta)}{(1+\eta-\beta)(1-(1-\zeta) \nu) \sigma} \\
\frac{(1-(1-\zeta) \nu) \beta \sigma}{(1+\eta-\beta) \gamma N^{*}(1-\zeta) \nu} & \rho & \frac{-(1-(1-\zeta) \nu) \rho(1+\eta)}{(1+\eta-\beta) \gamma N^{*}(1-\zeta)} & \frac{\phi(\nu(1+\eta)-\beta)}{(1+\eta-\beta) \gamma N^{*}} \\
\frac{-\beta \sigma}{(1+\eta-\beta)(1-\zeta) \nu}-1 & 0 & \frac{\rho(1+\eta)}{(1+\eta-\beta)(1-\zeta)} & \frac{\phi[-\zeta \nu(1+\eta-\beta)+\beta(1-\nu)]}{(1+\eta-\beta)(1-(1-\zeta) \nu)} \\
0 & 1 & 0 & 0
\end{array}\right]
\end{aligned}
$$

where $N^{*}$ is defined in (114). The quartic characteristic polynomial associated with the Jacobian matrix is (Jacobson 2012, p. 196)

$$
c(\lambda)=\operatorname{det}(\mathbf{J}-\lambda \mathbf{I})=\lambda^{4}-M_{1} \lambda^{3}+M_{2} \lambda^{2}-M_{3} \lambda+M_{4}
$$


where $M_{k}$ denotes the sum of principal minors of dimension $k$, and $M_{1}=\operatorname{tr}(\mathbf{J})$ and $M_{4}=\operatorname{det} \mathbf{J}$.

$$
\begin{aligned}
M_{1}= & \frac{1}{1-\zeta}\left[2 \rho+\frac{\zeta(1+\eta)}{1+\eta-\beta}\right]>0 \\
M_{2}= & \frac{\rho^{2}}{1+\eta-\beta}\left[\frac{-\phi(\alpha+\eta \nu)}{\gamma N^{*} \rho^{2}}+\frac{1+\eta}{1-\zeta}\right. \\
& \left.\quad-\frac{\beta \sigma(1+(1-\zeta) \alpha)+\nu(1-\zeta)(1-\nu+(1-\alpha) \eta)]}{(1-\zeta) \alpha \sigma}\right] \lesseqgtr 0 \\
M_{3}= & \frac{-\rho(1+\eta) \phi \nu}{\gamma N^{*}(1+\eta-\beta)}+\frac{\rho \beta \phi}{\gamma N^{*}(1+\eta-\beta)} \\
& \quad+\frac{-\rho^{3}[\beta \sigma+\nu(1-\zeta)(1-\nu+(1-\alpha) \eta)]}{(1-\zeta)(1+\eta-\beta) \sigma \alpha}<0 \\
M_{4}= & \frac{\rho^{2} \phi \beta \nu(\eta+\sigma)}{(1+\eta-\beta) \gamma \sigma \alpha N^{*}}>0
\end{aligned}
$$

Proof of Proposition 10. In the case of real roots, we show the characteristic polynomial has four solutions, and that two must be positive (unstable) and two negative (stable). ${ }^{61}$ Denote these solutions (eigenvalues) $\lambda_{1} \leq \lambda_{2}<0<\lambda_{3} \leq \lambda_{4}$. Since the determinant is positive $\lambda_{1} \lambda_{2} \lambda_{3} \lambda_{4}>0$. This rules out zero eigenvalues and restricts possibilities to (1) Two positive, two negative (2) All negative (3) All positive. The trace is positive so $\lambda_{1}+\lambda_{2}+\lambda_{3}+\lambda_{4}>0$ which rules out all negative. Both trace and determinant are positive, but $M_{3}$ is negative, which by Descartes' Rule of Signs implies (1) Two positive, two negative eigenvalues, is the only option.

\section{F Model Consistent Technology}

In order to shock our VAR we need to derive a technology series from our model. Using $F(K, L)=\frac{Y+N \phi}{A N^{1-\nu}}$ gives an alternative expression of TFP

$$
\mathrm{TFP}=\frac{Y}{\left(\frac{Y+N \phi}{A N^{1-\nu}}\right)^{\frac{1}{\nu}}}=\frac{A^{\frac{1}{\nu}} y}{(y+\phi)^{\frac{1}{\nu}}}
$$

If we equate this with our definition of TFP $=\frac{y}{F(k, l) \frac{1}{\nu}}$ then we get a relationship between $y, A, k, l$. Taking a log-linearization of this expression around zero-profit steady-state

\footnotetext{
${ }^{61}$ Since the polynomial is quartic there are well-known, but cumbersome, results to characterise real and complex solutions. If the roots are complex, no stable manifold may exist.
} 
gives a model consistent measure of technology

$$
\hat{A}=\frac{\hat{y}}{\nu\left(1+\frac{\phi}{y^{*}}\right)}-\frac{1}{\nu}\left(\varepsilon_{F, k} \hat{k}+\varepsilon_{F, l} \hat{l}\right)
$$

Where $\varepsilon_{F, x} \equiv \frac{F_{x} x}{F}$ which implies from Euler's homogeneous function theorem that $\nu=$ $\varepsilon_{F, k}+\varepsilon_{F, l}$. Under zero profits from (17) then $(1-\zeta)^{-1}=\nu\left(1+\frac{\phi}{y^{*}}\right)$. Additionally $\hat{y}=\hat{Y}-\hat{N}$, $\hat{l}=\hat{L}-\hat{N}, \hat{k}=\hat{K}-\hat{N}$ Hence

$$
\begin{aligned}
\hat{A} & =(1-\zeta) \hat{y}-\frac{1}{\varepsilon_{F, k}+\varepsilon_{F, l}}\left(\varepsilon_{F, k} \hat{k}+\varepsilon_{F, l} \hat{l}\right) \\
& =(1-\zeta)(\hat{Y}-\hat{N})-\frac{1}{\varepsilon_{F, k}+\varepsilon_{F, l}}\left(\varepsilon_{F, k} \hat{K}+\varepsilon_{F, l} \hat{L}-\left(\varepsilon_{F, k}+\varepsilon_{F, l}\right) \hat{N}\right) \\
\hat{A} & =(1-\zeta) \hat{Y}-\frac{1}{\varepsilon_{F, k}+\varepsilon_{F, l}}\left(\varepsilon_{F, k} \hat{K}+\varepsilon_{F, l} \hat{L}\right)+\zeta \hat{N} \\
& =\hat{Y}-\frac{1}{\varepsilon_{F, k}+\varepsilon_{F, l}}\left(\varepsilon_{F, k} \hat{K}+\varepsilon_{F, l} \hat{L}\right)-\zeta(\hat{Y}-\hat{N}) \\
& =\operatorname{TF} \mathrm{F}-\zeta(\hat{Y}-\hat{N})
\end{aligned}
$$

In the data we discretize this continuous time expression and use a Cobb-Douglas production function such that elasticities equal power terms. The result is that we construct our technology series as follows, where we have data or calibrated parameters for all right-hand side terms, allowing us to gain the left-hand side term

$$
\Delta \ln A_{t}=(1-\zeta) \Delta \ln Y_{t}-\frac{1}{\alpha+\beta}\left(\alpha \Delta \ln K_{t}+\beta \Delta \ln L_{t}\right)+\zeta \Delta \ln N_{t}
$$

In the reduced-form VAR exercise, we shock this technology term $A$ then observe how output, profit, capacity utilization and entry respond.

\section{G Labour Denominated Entry Cost}

We show that our results are robust to the specification of entry costs as labour denomiated rather than output denominated. We simulate the Bilbiie, Ghironi, and Melitz 2012 model with capital, no love of variety, monopolistic competition (fixed markup) and an output-denominated overhead cost. This shows that our results are robust to a different modelling framework where fixed entry costs are labour-denominated. 


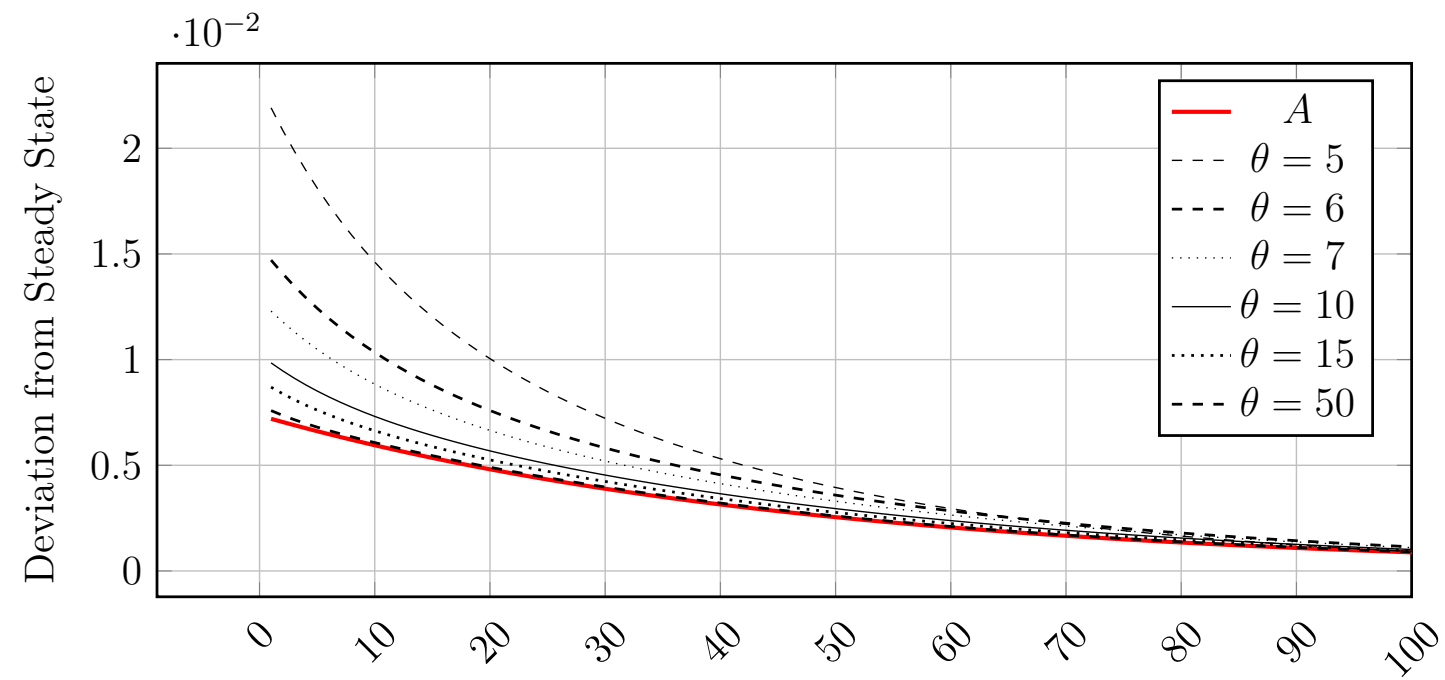

Figure 9: Measured TFP Converges on Technology in the Perfect Competition Limit

Figure $\mathrm{G}$ shows that as the markup disappears, due to decreased product differentiation ( $\theta$ increasing), the measured TFP series converges on the underlying technology series $A$. The underlying technology process follows an $A R(1)$

$$
\ln A_{t+1}=\varphi \ln A_{t}+\varepsilon, \quad \varepsilon \sim N\left(0, \sigma_{\varepsilon}^{2}\right)
$$

The persistence parameter is $\varphi=0.979$ and the variance of innovations is $\sigma_{\varepsilon}^{2}=0.0072^{2}$ as in Bilbiie, Ghironi, and Melitz 2012 which follows King and Rebelo 1999. The underlying technology series $A$ is given by the thick red line, at time zero it jumps up to 0.0072 since the shock takes the value of the standard deviation of the random variable. The random variable is 0 for all time periods after the first one and it dissipates according to the persistence term 0.979 . Table 2 presents the substitutability parameter $\theta$ in terms of benchmark measures of imperfect competition. The final row shows how the steady-state overhead cost share changes - as the markup decreases firm-size increases (movement down the AC curve) so the fixed overhead cost becomes a smaller share of output. A smaller overhead cost share represents weaker increasing returns. 


$\begin{array}{lcccccc}\text { Inter-sector Substitutability } \theta & 5 & 6 & 7 & 10 & 15 & 50 \\ \text { Price-cost Margin } \zeta=\frac{1}{\theta} & 0.2 & 0.17 & 0.14 & 0.10 & 0.07 & 0.02 \\ \text { Price-cost Markup } \mu=\frac{\theta}{\theta-1} & 1.25 & 1.20 & 1.17 & 1.11 & 1.07 & 1.02 \\ \text { Steady-state Overhead Cost Share } \frac{\phi}{y^{*}} & 0.51 & 0.40 & 0.22 & 0.16 & 0.09 & 0.07\end{array}$

Table 2: Alternative Measures of Competition

\section{H Data}

\section{H.1 Time Series Correlations}

Data are logged and HP-filtered at a quarterly frequency. Raw data is taken from Federal Reserve FRED database, and the unique MNEMONICS are GDP and TCU. The definition of TCU is "Capacity utilization is the percentage of resources used by corporations and factories to produce goods in manufacturing, mining, and electric and gas utilities for all facilities". Net entry is calculated from quarterly firm birth and death figures taken from the Bureau of Labour Statistics BED program.

\section{H.2 VAR Analysis}

Data are quarterly and log-differenced 1992Q3-2017Q3. Net entry is calculated as the difference in birth and death rates from the BLS Business Dynamics Statistics database. Output, corporate profit, labour hours (for calculating A) and capacity utilization are taken from FRED with codes CP, GDP, HOANBS, TCU. CP and GDP are deflated by 2012 prices (GDPDEF). To calculate $A$, as in (133), we specify $\zeta=0.1$ and $\alpha=0.3$ and $\beta=0.5$ as in our simulation exercises.

\section{H.3 Cross-sectional Productivity PCM Analysis (CompNet)}

We merge two CompNet modules (TFP and Markup). This causes some countries to be lost that only appear in one module. We also lose some years and industries that only appear in one module. In the supplementary appendix, we provide a document showing 
our data cleaning and analysis. The years covered vary across countries and sectors within a country. We drop observations with $\mathrm{PCM}<0$. We drop TFP variance observations that exceed the 90th percentile. There are good reasons to drop Romania which has TFP variances an order of magnitude less than all other countries, and loses industries during the matching process, but we leave the observation in for transparency - Romania is one of the countries that does not exhibit a statistically significant relationship. In the supplementary appendix we repeat the plots with the underlying scatter points plotted and no dropping of $>90$ th percentile TFP variance observations. This makes clear the distorting effects of extreme points. 


\section{References}

Acemoglu, D. (2009). Introduction to Modern Economic Growth. Introduction to Modern Economic Growth v. 1. Princeton University Press.

Aloi, Marta, Huw Dixon, and Anthony Savagar (2019). "Labor Responses, Regulation and Business Churn". In: Journal of Money, Credit and Banking (forthcoming).

Ambler, Steve and Emanuela Cardia (1998). "The Cyclical Behaviour of Wages and Profits under Imperfect Competition". In: Canadian Journal of Economics 31.1, pp. 148164.

Barseghyan, Levon and Riccardo DiCecio (2011). "Entry costs, industry structure, and cross-country income and TFP differences". In: Journal of Economic Theory 146.5, pp. $1828-1851$.

Basu, Susanto and John Fernald (2001). "Why Is Productivity Procyclical? Why Do We Care?" In: New Developments in Productivity Analysis. NBER Chapters. National Bureau of Economic Research, Inc, pp. 225-302.

Benhabib, Jess, Kazuo Nishimura, and Tadashi Shigoka (2008). "Bifurcation and sunspots in the continuous time equilibrium model with capacity utilization". In: International Journal of Economic Theory 4.2, pp. 337-355.

Berentsen, Aleksander and Christopher Waller (2015). "Optimal Stabilization Policy with Search Externalities". In: Macroeconomic Dynamics 19 (03), pp. 669-700.

Bergin, Paul R. and Giancarlo Corsetti (2008). "The extensive margin and monetary policy". In: Journal of Monetary Economics 55.7, pp. 1222-1237.

Bergin, Paul R., Ling Feng, and Ching-Yi Lin (2016). "Firm entry and financial shocks". In: The Economic Journal.

Bergin, Paul R. and Ching-Yi Lin (2012). "The dynamic effects of a currency union on trade". In: Journal of International Economics 87.2, pp. 191-204.

Berndt, Ernst R. and Melvyn A. Fuss (1986). "Productivity measurement with adjustments for variations in capacity utilization and other forms of temporary equilibrium". In: Journal of econometrics 33.1, pp. 7-29. 
Berndt, Ernst R. and Catherine J. Morrison (1981). "Capacity utilization measures: underlying economic theory and an alternative approach". In: The American Economic Review 71.2, pp. 48-52.

Bilbiie, Florin O, Fabio Ghironi, and Marc J Melitz (2007). Endogenous Entry, Product Variety, and Business Cycles. NBER Working Papers 13646. National Bureau of Economic Research, Inc.

- (2012). "Endogenous entry, product variety, and business cycles". In: Journal of Political Economy 120.2, pp. 304-345.

- (2019). "Monopoly Power and Endogenous Product Variety: Distortions and Remedies". In: American Economic Journal: Macroeconomics.

Bils, Mark and Jang-Ok Cho (1994). "Cyclical factor utilization". In: Journal of Monetary Economics 33.2, pp. 319-354.

Blanchard, Olivier Jean and Nobuhiro Kiyotaki (1987). "Monopolistic competition and the effects of aggregate demand". In: The American Economic Review, pp. 647-666.

Brito, Paulo and Huw Dixon (2013). "Fiscal policy, entry and capital accumulation: Hump-shaped responses". In: Journal of Economic Dynamics and Control 37.10, pp. 2123-2155.

Burnside, Craig, Martin Eichenbaum, and Sergio T Rebelo (1995). "Capital utilization and returns to scale". In: NBER Macroeconomics Annual 1995, Volume 10. MIT Press, pp. 67-124.

Campbell, Jeffrey R (1998). "Entry, exit, embodied technology, and business cycles". In: Review of economic dynamics 1.2, pp. 371-408.

Caputo, M.R. (2005). Foundations of Dynamic Economic Analysis: Optimal Control Theory and Applications. Cambridge University Press.

Chatterjee, Satyajit and Russell Cooper (1993). Entry and Exit, Product Variety and the Business Cycle. NBER Working Papers 4562. National Bureau of Economic Research, Inc.

- (2014). "Entry And Exit, Product Variety, And The Business Cycle". In: Economic Inquiry 52.4, pp. 1466-1484. 
Cook, David (2001). "Time to enter and business cycles". In: Journal of Economic Dynamics and Control 25.8, pp. 1241-1261.

Das, Sanghamitra and Satya P Das (1997). "Dynamics of entry and exit of firms in the presence of entry adjustment costs". In: International Journal of Industrial Organization 15.2, pp. 217-241.

Datta, Bipasa and Huw Dixon (2002). "Technological Change, Entry, and Stock-Market Dynamics: An Analysis of Transition in a Monopolistic Industry". In: American Economic Review 92.2, pp. 231-235.

Devereux, Michael B, Allen C Head, and Beverly J Lapham (1996). "Aggregate fluctuations with increasing returns to specialization and scale". In: Journal of economic dynamics and control 20.4, pp. 627-656.

Etro, Federico (2018). "Macroeconomics with Endogenous Markups and Optimal Taxation". In: Southern Economic Journal 85.2, pp. 378-406.

Etro, Federico and Andrea Colciago (2010). "Endogenous Market Structures and the Business Cycle*". In: The Economic Journal 120.549, pp. 1201-1233.

Fagnart, Jean-Francois, Omar Licandro, and Franck Portier (1999). "Firm Heterogeneity, Capacity Utilization, and the Business Cycle". In: Review of Economic Dynamics 2.2, pp. $433-455$.

Feenstra, Robert C (2003). Advanced International Trade: Theory and Evidence. Princeton University Press.

Greenwood, Jeremy, Zvi Hercowitz, and Gregory W Huffman (1988). "Investment, capacity utilization, and the real business cycle". In: The American Economic Review, pp. $402-417$.

Hall, Robert E. (1986). "Market Structure and Macroeconomic Fluctuations". In: Brookings Papers on Economic Activity 17.2, pp. 285-338.

- (1987). "Productivity and the Business Cycle". In: Carnegie Rochester Conference Series on Public Policy 27, pp. 421-444. 
Hall, Robert E. (1990). "Invariance Properties of Solow's Productivity Residual". In: Growth, Productivity, Unemployment: Essays to Celebrate Bob Solow's Birthday. MIT Press, pp. 71-112.

Hall, Robert E. and Marc Lieberman (2009). Microeconomics: Principles and Applications. Cengage Learning.

Haltiwanger, John, Ron S Jarmin, and Javier Miranda (2013). "Who creates jobs? Small versus large versus young". In: Review of Economics and Statistics 95.2, pp. 347-361.

Harrison, Ann E. (1994). "Productivity, imperfect competition and trade reform : Theory and evidence". In: Journal of International Economics 36.1-2, pp. 53-73.

Harrison, Ann E. and Brian J. Aitken (1999). "Do Domestic Firms Benefit from Direct Foreign Investment? Evidence from Venezuela". In: American Economic Review 89.3, pp. 605-618.

Hornstein, Andreas (1993). "Monopolistic competition, increasing returns to scale, and the importance of productivity shocks". In: Journal of Monetary Economics 31.3, pp. 299-316.

Hulten, Charles R (1986). "Productivity change, capacity utilization, and the sources of efficiency growth". In: Journal of econometrics 33.1-2, pp. 31-50.

Jacobson, N. (2012). Basic Algebra I: Second Edition. Dover Books on Mathematics. Dover Publications.

Jaimovich, Nir (2007). "Firm dynamics and markup variations: Implications for sunspot equilibria and endogenous economic fluctuations". In: Journal of Economic Theory 137.1, pp. 300-325.

Jaimovich, Nir and Max Floetotto (2008). "Firm dynamics, markup variations, and the business cycle". In: Journal of Monetary Economics 55.7, pp. 1238-1252.

Kim, Jinill (2004). "What determines aggregate returns to scale?" In: Journal of Economic Dynamics and Control 28.8, pp. 1577-1594.

King, Robert G. and Sergio T Rebelo (1999). "Resuscitating real business cycles". In: Handbook of Macroeconomics. Ed. by J. B. Taylor and M. Woodford. Vol. 1. Handbook of Macroeconomics. Elsevier. Chap. 14, pp. 927-1007. 
Kydland, Finn E and Edward C Prescott (1988). "The workweek of capital and its cyclical implications". In: Journal of Monetary Economics 21.2-3, pp. 343-360.

Lewis, Vivien (2009). "Business Cycle Evidence On Firm Entry". In: Macroeconomic Dynamics 13 (05), pp. 605-624.

Lewis, Vivien and Celine Poilly (2012). "Firm entry, markups and the monetary transmission mechanism". In: Journal of Monetary Economics 59.7, pp. 670-685.

Lewis, Vivien and Arnoud Stevens (2015). "Entry and markup dynamics in an estimated business cycle model". In: European Economic Review.

Lewis, Vivien and Roland Winkler (2017). "Government spending, entry, and the consumption crowding-in puzzle". In: International Economic Review 58.3, pp. 943-972.

Lopez-Garcia, Paloma and Filippo Di Mauro (2015). "Assessing European competitiveness: the new CompNet microbased database". In:

Mankiw, N Gregory and Michael D Whinston (1986). "Free entry and social inefficiency". In: The RAND Journal of Economics, pp. 48-58.

Morrison, Catherine J. (1992). "Unraveling the productivity growth slowdown in the United States, Canada and Japan: the effects of subequilibrium, scale economies and markups". In: The Review of Economics and Statistics, pp. 381-393.

- (2012). Cost Structure and the Measurement of Economic Performance: Productivity, Utilization, Cost Economics, and Related Performance Indicators. Springer US.

Nadiri, M. Ishaq and Ingmar Prucha (2001). "Dynamic Factor Demand Models and Productivity Analysis". In: New Developments in Productivity Analysis. NBER Chapters. National Bureau of Economic Research, Inc, pp. 103-172.

Nelson, Randy A (1989). "On the measurement of capacity utilization". In: The Journal of Industrial Economics, pp. 273-286.

Poutineau, Jean-Christophe and Gauthier Vermandel (2015). "Financial frictions and the extensive margin of activity". In: Research in Economics 69.4, pp. 525-554.

Da-Rocha, Jose-Maria, Marina Mendes Tavares, and Diego Restuccia (2017). Policy Distortions and Aggregate Productivity with Endogenous Establishment-Level Productivity. Working Paper 23339. National Bureau of Economic Research. 
Rossi, Lorenza and Emilio Zanetti Chini (2016). Firms' Dynamics and Business Cycle: New Disaggregated Data. Tech. rep. University of Pavia, Department of Economics and Management.

Rotemberg, Julio J and Michael Woodford (1992). "Oligopolistic Pricing and the Effects of Aggregate Demand on Economic Activity". In: Journal of Political Economy 100.6, pp. 1153-1207.

— (1999). "The cyclical behavior of prices and costs". In: Handbook of macroeconomics 1, pp. 1051-1135.

Savagar, Anthony (2019). Measured Productivity with Endogenous Markups and Economic Profits. 2019 Meeting Papers 819. Society for Economic Dynamics.

Shapiro, Matthew D (1993). "Cyclical productivity and the workweek of capital". In: The American Economic Review 83.2, pp. 229-233.

Tian, Can (2018). "Firm-level entry and exit dynamics over the business cycles". In: European Economic Review 102, pp. 298-326.

Vives, X. (1999). Oligopoly Pricing: Old Ideas and New Tools. MIT Press.

Wen, Yi (1998). "Capacity Utilization under Increasing Returns to Scale". In: Journal of Economic Theory 81.1, pp. 7-36. 